\title{
WEBER REVISADO: LA ÉTICA PROTESTANTE Y EL ESPÍRITU DEL NACIONALISMO*
}

Felix Kersting

Iris Wobnsiedler ${ }^{\mathrm{b}}$

Nikolaus Wolf

" DOI: https://doi.org/10.18601/01245996.v23n45.04. Recepción: 21-012021, aceptación: 02-06-2021. Sugerencia de citación: Kersting, F., Wohnsiedler, Y. y Wolf, N. (2021). Weber revisado: la ética protestante y el espíritu del nacionalismo. Revista de Economía Institucional, 23(45), 43-82. Tomado de Journal of Economic History, 80(3), 710-745 Este es un artículo de acceso abierto, distribuido bajo los términos de la licencia Creative Commons Attribution, que permite su reutilización, distribución y reproducción sin restricciones en cualquier medio, siempre que se cite el trabajo original. Traducción de Alberto Supelano. Los autores agradecen a Dan Bogart, cuatro árbitros anónimos, Thilo Albers, Robert Allen, Till Breyer, Stephen Broadberry, Gabriel Felbermayr, Beata Javorcik, Sibylle Lehmann-Hasemeyer, Martin Lutz, Alexander Nuetzenadel, Albrecht O. Ritschl, Kevin O'Rourke, Max-Stephan Schulze, Joachim Winter y a los participantes en el seminario en Oxford, Roma, Leipzig, York, el taller CRC TRR 190, Berlín, 2018, y en la conferencia CEPR sobre "La economía de la religión”, Venecia, 2019, por sus útiles comentarios. Así como a Sibylle Lehmann y Fabian Wahl por proporcionar datos sobre las cajas de ahorros. Se agradece el apoyo financiero de Deutsche Forschungsgemeinschaft a través de CRC TRR 190.

${ }^{a}$ Estudiante de doctorado, Departamento de Economía, Universidad Humboldt de Berlín, Berlín Alemania, [f.kersting@hu-berlin.de].

b Asistente de investigación, Departamento de Economía, Universidad Humboldt de Berlín, Berlín Alemania, [wohnsiei@hu-berlin.de.]

c Profesor, Departamento de Economía, Universidad Humboldt de Berlín, Berlín, Alemania, [nikolaus.wolf@wiwi.hu-berlin.de]. 


\section{Weber revisado: la ética protestante y el espíritu del nacionalismo}

Resumen Este articulo revisa la hipotesis de Max Weber sobre el papel del protestantismo en el desarrollo economico. Demuestra que el nacionalismo es crucial para la interpretación de la etica protestante de Weber y su comprobacion empirica. En el caso de Prusia de finales del siglo XIX, rechaza su sugerencia de que el protestantismo importaba debido a una "compulsion ascetica a ahorrar". Ademas, encuentra que los niveles de ingreso, ahorro y tasas de alfabetizacion diferian entre alemanes y polacos, no entre protestantes y catolicos; y sugiere que este resultado se debe a ladiscriminacion contra Polonia.

Palabras clave: Max Weber, ética protestante, nacionalismo, desarrollo económico, compulsión a ahorrar, ingreso, ahorro, tasas de alfabetización; JEL: A12, A13, C1, D31, E21, I24, 01, Z12, Z13

\section{Weber revisited: The Protestant ethic and the spirit of nationalism}

Abstrac We revisit Max Weber's hypothesis on the role of Protestantism for economic development. We show that nationalism is crucial to both, the interpretation of Weber's Protestant ethic and empirical tests thereof. For late nineteenth-century Prussia, we reject Weber's suggestion that Protestantism mattered due to an "ascetic compulsion to save." Moreover, we find that income levels, savings, and literacy rates differed between Germans and Poles, not between Protestants and Catholics, using pooled MCO and VI regressions. We suggest that this result is due to anti-Polish discrimination.

Keywords: Max Weber, Protestant ethic, nationalism, economic development, compulsion to save, income, savings, literacy rates; JEL: A12, A13, C1, D31, E21, I24, 01, Z12, Z13

\section{Weber revisado: a ética protestante e o espírito do nacionalismo}

Resumo Este artigo revisa a hipótese de Max Weber sobre o papel do protestantismo no desenvolvimento econômico. Mostra que o nacionalismo é crucial para a interpretação da ética protestante de Weber e sua verificação empírica. No caso da Prússia no final do século XIX, ele rejeita sua sugestão de que o protestantismo importava por causa de uma “compulsão ascética para salvar". Além disso, ele descobriu que os níveis de renda, poupança e taxas de alfabetização diferiam entre alemães e poloneses, não entre protestantes e católicos; e sugere que este resultado se deve à discriminação contra a Polônia.

Palavras-chave: Max Weber, ética protestante, nacionalismo, desenvolvimento econômico, compulsão para salvar, renda, poupança, taxas de alfabetização; JEL: A12, A13, C1, D31, E21, I24, 01, Z12, Z13 
T os economistas reconocen cada vez más el papel de la "cultura” en Lel desarrollo económico, debido al enfoque nuevo y más amplio de la economía del comportamiento humano y la toma de decisiones. Una de las ideas hoy más influyentes proviene de la obra de Max Weber de hace más de un siglo. Weber $(1904,1905)$ formuló la conocida hipótesis de que una ética de trabajo protestante específica fomentó el desarrollo económico moderno debido a una "compulsión a ahorrar". La justificó con evidencia estadística sobre las diferencias entre protestantes y católicos en Baden alrededor de 1900 y usó evidencia anecdótica para sugerir una relación mucho más general.

En este artículo revisamos la hipótesis de Weber y la evidencia acerca de ella para la Alemania del siglo XIX. Argumentamos que la "interpretación común" (Delacroix y Nielsen, 2001) de Weber a menudo ha pasado por alto su argumento sobre el comportamiento del ahorro como mecanismo clave así como el sesgo nacionalista y anti-polaco de Weber. Weber escribió en un contexto en el que las diferencias religiosas (entre católicos y protestantes) se superponían a las diferencias étnico-nacionales (entre polacos y alemanes), y era muy consciente de ello. Era un nacionalista alemán apasionado, y sus escritos, incluida la Ética protestante (EP), también se deben entender como una contribución a la educación política del público alemán (Barbalet, 2008). De hecho, la EP se debería ver más como una "intervención en los asuntos político alemanes que como una explicación del surgimiento del capitalismo” (Scott, 2009, p. 903). Demostramos empíricamente que debemos modificar la "interpretación común" en dos aspectos: enfocarse en el ahorro como mecanismo por el cual la religión pudo afectar los resultados económicos y controlar las diferencias entre grupos étnicos como posible factor de confusión.

La Prusia del siglo XIX nos proporciona una rica variación para hacer una nueva prueba de la EP de Weber. Empezando con la evidencia descriptiva básica, mostramos que los niveles de ingresos, ahorros y tasas de alfabetización en Prusia después de 1870 tienen una correlación más fuerte con las diferencias entre grupos étnicos que con las diferencias entre confesiones religiosas. Las regresiones simples de mínimos cuadrados ordinarios (MCO) sugieren que es probable que la etnicidad sea un factor crucial para explicar la gran variación de las variables resultado en todo el Imperio alemán. Para exponer la evidencia causal sobre el papel de la cultura para el desarrollo, seguimos a Acemoglu (2009) y distinguimos entre causas próximas y fundamentales del crecimiento económico. Nos centra- 
mos en las tasas de ahorro y alfabetización como posibles causas próximas del crecimiento, y en la religión -que capta aspectos de la cultura- como una posible causa fundamental del crecimiento. Luego usamos un enfoque de variable instrumental (VI) para probar la causalidad: los niveles de ingreso, ahorro y tasas de alfabetización no diferían entre protestantes y católicos, pero diferían entre alemanes y polacos. Expliquemos con más detalle cómo llegamos a esta conclusión.

En el primer paso de nuestro análisis empírico revisamos la evidencia acerca del mecanismo subyacente, motivados por la relectura del texto original de Weber, donde sugirió que el protestantismo podría haber llevado a una "acumulación de capital por la compulsión ascética de ahorrar" (Weber, 1905, p. 191). Esta idea fue formalizada por Alaoui y Sandroni (2018). Para probarla de manera más directa, utilizamos un conjunto reciente de datos de Lehmann y Wahl (2017) sobre el ahorro per cápita y el número de cajas de ahorro en todos los condados de Prusia, disponibles para 1875, 1882, 1888, 1898 y 1904. Para probar un efecto causal del protestantismo en los ahorros, usamos una VI basada en las confesiones religiosas desde 1624, siguiendo a Spenkuch (2017). La VI se construye haciendo una regresión entre protestantes en 1624 y predictores de las elecciones de gobernantes, como en la literatura anterior, en particular Cantoni (2012) y Rubin (2014). Los residuos se utilizan como instrumento de la proporción de protestantes después de 1870. Mostramos que el instrumento es sólido y robusto a violaciones de la restricción de exclusión. No encontramos ningún efecto significativo del protestantismo en el ahorro, ni en la estimación MCO ni en VI. Este resultado también es robusto a variaciones de la muestra, especificaciones alternativas, a la inclusión del ingreso per cápita como regresor y a la distinción entre luteranos y protestantes reformados. En cambio, encontramos que las diferencias étnicas medidas por la proporción de hablantes de alemán están fuertemente correlacionadas con el ahorro per cápita.

Luego probamos la idea de que el protestantismo importaba no debido al cambio de actitudes hacia el trabajo y el consumo, sino porque fomentaba la alfabetización, como sostienen Becker y Woessmann (2009). En primer lugar presentamos nueva evidencia descriptiva de la diferencia en las tasas de alfabetización entre protestantes y católicos a nivel de condado a partir de un cuadro histórico tranversal, que ha sido bastante olvidada en la literatura. 
Mostramos que a nivel de condado, las tasas de alfabetización entre católicos son casi idénticas a las tasas de alfabetización entre protestantes. La única excepción son los condados con una alta proporción de población polaca. En segundo lugar probamos el efecto causal de la religión en la alfabetización, usando de nuevo el enfoque VI de Spenkuch. Encontramos que el protestantismo no tuvo un efecto significativo. El coeficiente de las diferencias étnicas es mucho mayor, y estadística y económicamente significativo.

Estos resultados nos llevan a un nuevo rompecabezas. Al parecer, las diferencias religiosas muy poco ayudan a entender la gran variación del desarrollo económico entre la Alemania imperial del siglo XIX y Prusia. Por tanto, en nuestro contexto se puede refutar claramente una interpretación ingenua de la EP de Weber. Además, la interpretación más sofisticada del papel del protestantismo mediante las tasas de alfabetización no es respaldada por los datos. Esto no excluye que el protestantismo ascético tuviera efectos causales siglos antes, que pueden haber indirectamente afectado a los católicos y, de hecho, a la secularización. Una interpretación alternativa podría situar el argumento de Weber en el contexto del cambio tecnológico o probar mecanismos totalmente diferentes del modo en que la Reforma Protestante pudo haber ocasionado el desarrollo económico (Cantoni, Dittmar y Yuchtman, 2018). Pero nuestros resultados sugieren que las diferencias religiosas entre católicos y protestantes (incluidos los luteranos) tuvieron poca persistencia; por tanto, no se pueden considerarse "fundamentales" sin una cualificación adicional. En cambio, nuestra evidencia destaca las enormes diferencias entre grupos étnicos (alemanes y polacos) que existían alrededor de 1900 en Prusia, que eclipsan cualquier diferencia entre protestantes y católicos. Este nuevo resultado concuerda con gran parte de la literatura histórica sobre el Imperio alemán, que subraya el aumento de las tensiones nacionales y la disminución del conflicto religioso después del final de la Kulturkampf(Wehler, 2006).

En la última parte discutimos esta relación entre etnicidad y resultados económicos y sugerimos algunas líneas para futuras investigaciones. Este tema es importante, no solo debido a la alta correlación entre las diferencias en los resultados económicos, los grupos étnicos y la religión, sino porque el mismo Weber consideraba que la etnicidad era crucial. En un escrito anterior atribuyó las diferencias en los resultados económicos entre alemanes y polacos a diferencias raciales (Weber, 1895) y apoyó activamente una mayor germaniza- 
ción de las zonas orientales de Alemania. Así, su inclinación nacionalista no solo arroja una luz diferente sobre la EP (como indica la investigación reciente en sociología), sino que también proporciona un punto de referencia contemporáneo para explicar esas diferencias: la discriminación alemana. Documentamos que después de 1871 la mayoría alemana discriminó cada vez más a la minoría polaca en las políticas lingüística y educativa, así como en el acceso a cargos públicos y la política de redistribución de la tierra. Los polacos podrían haber reaccionado intentando crear sustitutos, como la educación fuera de las escuelas públicas o la creación de cooperativas polacas de crédito y tierras. Se necesita más investigación en esta línea para entender hasta qué punto la germanización puede explicar las grandes diferencias observadas en los ingresos, los ahorros y las tasas de alfabetización, que señalamos antes.

Este artículo contribuye a varias líneas de investigación. En primer lugar, a la creciente literatura sobre el papel de la cultura, y específicamente la religión en el desarrollo económico. Parte de la literatura se ha centrado en argumentos teóricos, en cómo la cultura puede afectar las preferencias, el comportamiento y los resultados, incluidos Bénabou y Tirole (2004, 2006, 2011), Tabellini (2008), Doepke y Zilibotti (2008), y Alaoui y Sandroni. (2018). En cierta medida, esta literatura se puede ver como un intento de racionalizar las consecuencias conductuales de las actitudes culturales, como la tesis de Weber de que el protestantismo ascético lleva a un aumento del ahorro y la acumulación de riqueza. Otra parte de esa literatura busca probar empíricamente el papel de la cultura en el desarrollo económico (para una revisión, ver Iannaccone, 1998; Barro y McCleary, 2003; Becker y Woessmann, 2009; Cantoni, 2015; Spenkuch, 2017, y Becker, Pfaff y Rubin, 2016). Nuestra primera contribución es el enfoque en el comportamiento del ahorro como mecanismo que vincula el protestantismo y el desarrollo económico. Este mecanismo es importante ya que es el núcleo de la EP de Weber y también es central en gran parte de la literatura teórica reciente, incluido Alaoui y Sandroni (2018). Podemos rechazar claramente esta hipótesis para la Prusia de finales del siglo XIX. Otra contribución es que reconsideramos una destacada hipótesis alternativa, sugerida por Becker y Woessmann (2009): que el protestantismo fue importante en el desarrollo a través de las tasas de alfabetización. También podemos rechazar esta hipótesis en nuestro contexto. Proporcionamos nueva evidencia directa a nivel de condado de que 
las tasas de alfabetización entre protestantes y católicos no diferían en 1871. Mostramos, en cambio, que sí diferían mucho entre grupos étnicos, lo que no consideró la literatura anterior.

Después mostramos que el nacionalismo y el conflicto étnico son claves para entender la EP de Weber y las diferencias de desarrollo económico. El primero es bien conocido en la literatura sociológica e histórica sobre Weber y la EP (p. ej., Mommsen, 2004; Zimmerman, 2006; Barbalet, 2008), pero ha sido muy ignorado en la literatura económica. Aquí, nuestra contribución es recordar a los economistas el contexto en que Weber escribió (Margo, 2017) y mostrar empíricamente que las diferencias étnicas son un factor crucial de confusión. Si bien nuestros datos corresponden a Alemania de finales del siglo XIX, pensamos que las diferencias religiosas y étnicas pueden estar relacionadas de manera más sistemática. Nuestros resultados sugieren que la literatura anterior puede haber sobrestimado el papel de la religión al no tener en cuenta las diferencias étnicas.

Por último, contribuimos a la literatura sobre el desarrollo económico a largo plazo de Alemania (Broadberry y Burhop, 2007; Grant, 2005; Wolf, 2009; Hornung, 2015; Bartels, 2019). Documentamos que el Imperio Alemán se caracterizó por la fragmentación entre grupos religiosos y étnicos, entre territorios con diferentes legados históricos, la creciente división rural-urbana así como una creciente desigualdad económica. E1 desarrollo económico de Alemania antes de la Primera Guerra Mundial fue, en cierta medida, moldeado por estas líneas de fragmentación (p. ej., Wolf, 2009). Cinnirella y Schueler (2016) demuestran que la fragmentación etnolingüística fue importante en las políticas educativas. Nuestros resultados empíricos sugieren que tuvo una importancia más general para las diferencias en el desarrollo económico.

En la primera sección del artículo se revisa brevemente el ensayo de Weber sobre la EP y la "interpretación común" que ha servido como caballo de batalla en gran parte de los trabajos recientes. La segunda sección presenta los antecedentes históricos del desarrollo económico en la Alemania de finales del siglo XIX. En la tercera sección se enuncian las principales hipótesis y se presenta la estrategia empírica para probar la causalidad. La cuarta presenta los principales resultados sobre ingresos, ahorros y tasas de alfabetización, así como varios controles de robustez. En la quinta se muestra que las políticas discriminatorias podrían explicar el papel observado de las diferencias étnicas, y en la última se exponen las conclusiones. 


\section{LA ÉTICA PROTESTANTE DE WEBER Y LA “INTERPRETACIÓN COMÚN"}

La ética protestante y el espíritu del capitalismo es un texto fundacional de la sociología y sigue siendo muy discutido, también en disciplinas vecinas como la historia y la economía. Se publicó por primera vez en dos partes en 1904 y 1905 e inmediatamente recibió mucha atención, elogios y críticas. En 1920, Weber publicó una versión revisada que incorporó parte de la discusión anterior y es la base para los debates posteriores y para las traducciones (Lehmann y Roth, 1995). La interpretación de la EP ha cambiado con el tiempo, cierta medida debido a la complejidad y a la ambigüedad de los argumentos de Weber (MacKinnon, 1995). No podemos revisar ni siquiera superficialmente toda la discusión, sino centrarnos en algunos aspectos que han sido retomados en la literatura empírica (principalmente económica) más reciente.

Un punto de partida conveniente es la "interpretación común" de la hipótesis de Weber formulada por Delacroix y Nielsen (2001, p. 511) y Nolan y Lenski (2014), que es central en la literatura empírica reciente sobre el tema. Dada la vasta literatura sobre la EP y su exégesis apropiada, estos autores hicieron el siguiente resumen simplificado pero comprobable: 1) La Reforma Protestante fomentó nuevas actitudes, 2) las nuevas actitudes (la EP) afectaron el comportamiento y 3) las nuevas actitudes y comportamientos favorecieron el desarrollo económico y contribuyeron a la industrialización en todo el mundo. Esta es la interpretación de la EP de Weber que ha sido probada y discutida recientemente en la literatura económica.

La "interpretación común” sigue siendo poco específica sobre el posible mecanismo que podría llevar del cambio de actitud al cambio de comportamiento y finalmente al desarrollo económico. Esto se debe a que el mismo Weber expuso muchas salvedades. Al comienzo de su ensayo, señaló que podría haber un problema de causalidad inversa: que las partes más ricas del Imperio, en particular las ciudades ricas, fueron las que primero adoptaron las ideas protestantes en el siglo XVI. También sugirió que el mayor ingreso de los protestantes en la época en que lo escribió podía ser resultado de varios factores históricos, y contribuir a las diferencias de comportamiento económico observadas. Hacia el final de su ensayo, sugirió que un análisis completo debía examinar cómo la ética protestante del trabajo pudo afectar la organización de las sociedades y sus instituciones políticas, 
así como la formación de la ciencia y la tecnología modernas, entre otras cosas. Pero en el centro de su ensayo hay claros enunciados de un mecanismo subyacente particular. En su opinión, la formación de una nueva actitud (protestantismo ascético) lleva a un cambio de comportamiento, a limitar el consumo y aumentar la actividad económica, de modo que "el resultado práctico inevitable es obvio: la acumulación de capital mediante la compulsión ascética a ahorrar" (Weber, 1905, p. 191) ${ }^{1}$.

Entre las contribuciones empíricas influyentes se incluyen Delacroix y Nielsen (2001), Barro y McCleary (2003), Becker y Woessmann (2009), Cantoni (2015) y Spenkuch (2017). Delacroix y Nielsen exploran la correlación entre la evidencia transversal entre países de la proporción de católicos y protestantes, y diversos varios indicadores del desarrollo económico, incluidos la riqueza, los depósitos en cajas de ahorro per cápita, la extensión de la red ferroviaria y otros. En general, solo encuentran un respaldo empírico limitado para la "interpretación común". Barro y McCleary utilizan un conjunto de datos globales transversales entre países para probar la relación entre creencias religiosas, asistencia a la iglesia y resultados económicos. Emplean la estimación de datos de panel y encuentran que las creencias religiosas son importantes, especialmente la creencia en el infierno, después de controlar la asistencia a la iglesia y considerar la causalidad inversa. Becker y Woessmann utilizan datos de los condados prusianos de finales del siglo XIX, la época en que Weber escribía, y encuentran un vínculo causal entre protestantismo y desarrollo económico. Sin embargo, argumentan que puede ser explicado totalmente por las mayores tasas de alfabetización entre los protestantes en vez de cualquier efecto de las actitudes religiosas. Cantoni usa datos de panel del crecimiento de la ciudad como indicador del desarrollo económico en todo el Sacro Imperio Romano Germánico durante los siglos 1300 a 1900 y no encuentra efectos de la diferencias en las confesiones. Spenkuch usa microdatos de panel socioeconómico (SOEP) en la Alemania de hoy para probar las diferencias entre protestantes y católicos en sus actitudes, comportamientos y resultados. Encuentra alguna evidencia que sugiere que los protestantes trabajan más horas debido a una ética de trabajo diferente captada en preguntas específicas de su encuesta.

${ }^{1}$ En la traducción de Talcott Parsons, ver Weber (1930, p. 172). De acuerdo con este razonamiento, usando un gran conjunto de datos globales sobre las preferencias temporales de los individuos Dohmen et al. (2018) encuentran una fuerte relación de forma reducida entre paciencia y desarrollo económico. 
¿Por qué la "interpretación común” y la mayor parte del trabajo empírico sobre ella descuida la aguda distinción de Weber entre el luteranismo y el protestantismo ascético calvinista? Weber subrayó el papel del "llamado o vocación", la base religiosa e irracional de la EP. Argumentó que para Lutero este concepto seguía siendo tradicionalista, mientras que para los calvinistas implicaba una lucha incesante por el éxito mundano ${ }^{2}$. La falla común para distinguir entre el luteranismo y otras confesiones protestantes en la literatura empírica se debe en parte al uso que hizo Weber de la evidencia en la EP: en la primera página, Weber justifica su trabajo con datos estadísticos de las diferencias en asistencia escolar entre católicos y protestantes en Baden, tomados de su alumno Martin Offenbacher (1901). Aparte de algunos errores estadísticos que exageran esas diferencias (Becker, 1997), los datos no nos permiten distinguir entre luteranos y otros protestantes. Por ello, el mismo Weber situó su argumento en el contexto de diferencias aparentemente sorprendentes entre católicos y protestantes, para profundizar más en la naturaleza dinámica del protestantismo ascético y subrayar implícitamente el atraso del catolicismo.

La “interpretación común" se basa en el supuesto de que el texto de Weber se debe ver como un estudio sobre los orígenes del capitalismo moderno y el desarrollo económico. Pero gran parte de la literatura reciente sobre Weber resalta el contexto en el que escribió, en particular la dimensión política de sus escritos y el lugar de la EP con respecto a su obra anterior. Wolfgang Mommsen (2004, p. 38), editor de la recopilación de escritos de Max Weber, afirmó que su conferencia inaugural (CI), en la Universidad de Friburgo en 1895, fue el documento más importante del político Max Weber hasta la Primera Guerra Mundial, el cual es relevante en este contexto. Bajo el título "El Estado nacional y la política económica" ("Der Nationalstaat und die Volkswirtschaftspolitik"), Weber afirma que quiere aclarar "el papel de las diferencias raciales físicas y psicológicas entre nacionalidades en la lucha económica por la existencia” (Weber, 1895, p. 545). Su ejemplo son las diferencias entre polacos

${ }^{2}$ Como muestra Graf (1995, p. 41 y ss.), Weber argumentó aquí contra la visión dominante en su época definida por el teólogo Albrecht Ritschl y sus estudiantes, que consideraban al luteranismo como piedra angular del nuevo Estado nación alemán. Pero aunque ambos consideraban a los católicos como tradicionalistas y culturalmente inferiores, para Weber el luteranismo era una "forma deficiente de religiosidad protestante, más cercana a la conducta católica tradicionalista que a la actividad ética de los calvinistas” (ibíd., p. 45). 
y alemanes en la provincia de Prusia Occidental. Citando evidencia estadística, sugiere que aunque los campesinos polacos viven en terrenos menos fértiles, son menos propensos a emigrar que los campesinos alemanes en respuesta a la reciente crisis agrícola, lo que resulta en un "desplazamiento económico" de alemanes por polacos. Su hipótesis es que esto tiene raíces en las actitudes diferentes de las dos nacionalidades, específicamente en las "menores exigencias de nivel de vida [...], que la raza eslava tiene por naturaleza o adquirió en su pasado" (ibíd., p. 551). Por tanto, diez años antes de la EP, en su CI de 1895, Weber argumentó que actitudes diferentes pueden llevar a comportamientos (la migración) y resultados diferentes (el desplazamiento de alemanes por polacos). Significativamente, exigió que la política económica debía detener esto, porque "nuestro Estado es un Estado nacional” (ibíd., p. 558). Según Ernst Tröltsch, "el poder y la grandeza nacionales" era el único "Wertgott" al que Weber adoraba incondicionalmente (Troeltsch, 1922, p. 161). Basado en el ejemplo del conflicto nacional entre polacos y alemanes en el este, Weber consideró que los junkers prusianos (luteranos) no habían proporcionado liderazgo político. Y concluyó que la burguesía alemana tenía la urgente necesidad de educación política (1895, pp. 570-573) ${ }^{3}$. Barbalet (2001) trazó una línea desde los argumentos que Weber expuso en su CI hasta la EP. Sugirió que en la EP de 1904/1905 asumió el desafío formulado en su conferencia de Friburgo y propuso una solución al problema de la educación política: para enfrentar la amenaza a la nación alemana, en particular, la amenaza de polonización, Weber argumentó que las élites luteranas alemanas necesitaban una nueva vocación, y que el protestantismo ascético podía proporcionarla.

Esta lectura de la EP de Weber es más que una nota a pie histórica, porque afecta nuestros antecedentes. No es claro si deberíamos esperar encontrar diferencias sustanciales en los indicadores de desarrollo económico entre protestantes y católicos en la Alemania del siglo XIX. En la siguiente sección hacemos una breve presentación de algunos antecedentes históricos relevantes.

${ }^{3}$ Weber mantuvo su nacionalismo anti-polaco hasta el final de su vida. En 1899 se retiró de la liga nacionalista pangermana porque creía que la organización había cedido a los intereses de los capitalistas agrarios permitiendo la afluencia de inmigrantes polacos baratos en vez de luchar contra la amenaza polaca (Zimmerman, 2006, p. 64). Aunque más adelante Weber se convirtió en crítico del colonialismo alemán, en 1918 durante una conferencia se manifestó contra los funcionarios polacos que entrarían en la disputada ciudad de Danzig, y propuso que los fusilaran (ibíd.). 


\section{DESARROLLO ECONÓMICOYTENSIONES POLÍTICAS EN ALEMANIA IMPERIAL}

E1 Imperio Alemán en 1904 y 1905, cuando se publicó la EP de Weber, se caracterizaba por una economía en crecimiento dinámico con crecientes tensiones sociales y políticas. Entre 1850 y 1910, Alemania pasó de una economía atrasada a ser el núcleo industrial de Europa.

La guerra contra Francia de 1870/1871 llevó a la formación de una nueva entidad política -el Imperio Alemán-muy heterogénea, dado su muy pequeño tamaño. El Estado prusiano tenía una posición de liderazgo, con un $60 \%$ de la población total. Pero la misma Prusia era heterogénea, dividida en ciudades dinámicas como Berlín y regiones agrarias atrasadas, viejos territorios prusianos como Brandeburgo y nuevos territorios conquistados tras las guerras napoleónicas como Renania (1815), Hannover (1866) o Schleswig-Holstein (1866). Y más importante, Prusia experimentó conflictos entre católicos y protestantes, y entre alemanes, polacos y otras minorías nacionales.

De modo que después de la formación del Imperio a comienzos de 1871, su carácter como Estado nación siguió siendo cuestionado y Prusia, el Estado más grande e influyente, fue la arena central de estos debates públicos. La primera línea de conflicto se abrió entre el Estado prusiano, por un lado, y la Iglesia Católica y las organizaciones católicas, por el otro, la Kulturkampf. Aunque el conflicto entre la Iglesia Católica y las autoridades estatales era un fenómeno europeo en esa época, la disputa fue especialmente intensa en el Imperio Alemán. En Alsacia-Lorena y las provincias orientales de Prusia, este conflicto se superpuso a la resistencia de las minorías nacionales contra el nacionalismo alemán, porque estas minorías eran abrumadoramente católicas. Desde la perspectiva polaca, esta Kulturkampf se consideró ante todo como un ataque a la identidad polaca (Trzeciakowski, 1970). Aquí el conflicto entre Estado e iglesia fue feroz (p. ej., Ledochowski, el arzobispo católico de Gniezno y Poznan fue encarcelado en 1874-1876) y coincidió con los primeros pasos de la represión contra el idioma polaco en las escuelas primarias y secundarias después de 1871 (Knabe, 2000).

La situación cambió con el giro político de Bismarck en 1878/1879, que puso fin a la Kulturkampf, pero abrió nuevas líneas de conflicto contra los socialistas y las minorías nacionales, acompañado de un antisemitismo y un proteccionismo crecientes. Las décadas de 1880 a la Primera Guerra Mundial se caracterizaron por el 
aumento del sentimiento nacionalista alemán, reflejado por ejemplo en el crecimiento de las organizaciones de veteranos (Kriegervereine) nacionalistas. Sus miembros pasaron de 71.900 (menos del 1\% de la población masculina) en 1873 a 2,8 millones en 1913 (más del 8\% de dicha población), más que todos los sindicatos del Imperio (Kersting, 2017). Especialmente los polacos del este de Prusia se consideraron una amenaza al Estado alemán y sufrieron una dura opresión. La Geschäftssprachengesetz de 1876 y la Gerichtsverfassungsgesetz de 1877 prohibieron el uso del idioma polaco en la administración y el poder judicial (Wehler, 2006). Bajo el nuevo ministro de Educación de Prusia, Gustav von Gossler, desde 1881 hubo una oleada de nuevas medidas en un intento de reprimir el uso del idioma polaco en las escuelas y reducir el número de profesores polacos. Después de años de discusión, en 1901 el Estado prusiano intentó eliminar el idioma polaco en la educación religiosa, lo que de inmediato desató la primera huelga escolar en la ciudad de Wrzesnia en 1901. Esta fue seguida por una huelga mucho mayor en 1906. E1 Estado prusiano respondió con medidas disciplinarias y finalmente rompió la huelga, pero las tensiones por la política lingüística y la identidad nacional de polacos y alemanes no disminuyeron.

Así que la Alemania de finales del siglo XIX se caracterizó por conflictos fundamentales entre confesiones religiosas y nacionalidades, que se intensificaron después de la formación del Imperio alemán en 1871 y en oleadas posteriores. ¿En qué medida estos conflictos se reflejaron en los resultados económicos de esa época? Wolf (2009) demostró que las diferencias de idioma importaban mucho más que las diferencias religiosas como barrera a los flujos comerciales internos dentro del Imperio entre 1885 y 1913. En las siguientes secciones examinamos si el idioma y las confesiones religiosas estaban relacionados sistemáticamente con diferentes niveles de desarrollo económico, si se pueden interpretar como relaciones causales, y cuáles podrían ser los mecanismos subyacentes.

\section{HIPÓTESIS, DATOS Y ESTRATEGIA EMPÍRICA}

E1 análisis empírico se centra en las diferencias en los niveles de ingreso, ahorros y tasas de alfabetización como indicadores del desarrollo económico en los condados de Prusia en el tiempo. El objetivo es probar las tres hipótesis siguientes:

H1: El protestantismo tuvo un efecto causal en el comportamiento del ahorro. 
H2: E1 protestantismo tuvo un efecto causal en las tasas de alfabetización.

H3: Las diferencias étnicas son una variable omitida en la "interpretación común”.

Distinguimos entre causas próximas y fundamentales del crecimiento económico (Acemoglu, 2009). Las causas próximas incluyen diferencias en tecnología, capital físico (como lo refleja el ahorro) y capital humano (como lo reflejan las tasas de alfabetización); las causas fundamentales incluyen factores geográficos (p. ej., recursos de carbón), instituciones (p. ej., derechos de propiedad) y cultura (p. ej., una ética de trabajo específica).

Para probar nuestra primera hipótesis, exploramos el efecto causal del protestantismo en el ahorro como causa próxima específica del desarrollo que, a su vez, puede afectar el crecimiento y los niveles de ingreso a largo plazo. Para ello, utilizamos datos regionales de cajas de ahorros (Sparkassen) proporcionados por Lehmann y Wahl (2017). La primera caja de ahorro se fundó en 1778 en Hamburgo para beneficiar a "personas pobres, trabajadoras de ambos sexos, que trabajaban como sirvientes, jornaleros, obreros, marinos, etc." y darles la oportunidad de ahorrar dinero (von Knebel, 1907, p. 2). Las cajas de ahorro combinaban las funciones de los bancos de depósito y las instituciones de crédito, y debían cumplir sus propósitos como institución para prevenir la pobreza. A diferencia del seguro social proporcionado por el Estado, el ahorro se deja a la libre elección del individuo. Así, los datos de los depósitos en las cajas de ahorro permiten observar el comportamiento del ahorro de grupos de ingreso medio a bajo, a los que se les alentó a ahorrar para pagar gastos imprevistos y reinvertir el dinero en su negocio agrícola o artesanal, y contribuir así a un mejor nivel de vida en el largo plazo (Trende, 1957, p. 129) $)^{4}$.

Aunque la acumulación de capital en cooperativas de crédito agrícola y comercial era necesaria para asegurar el suministro de cré-

\footnotetext{
${ }^{4}$ Nuestros datos podrían implicar algún sesgo si los ingresos más altos de la actividad empresarial e industrial difirieran sistemáticamente entre protestantes y católicos. Aunque esto requeriría más investigación, la evidencia disponible sugiere que no hay tal sesgo en los datos prusianos antes de 1914. Primero, la proporción de ingresos millonarios en la población no se correlacionó con el protestantismo en 1912 (Martin, 1912). Segundo, usando las estadísticas fiscales de Prusia encontramos que la participación de los ingresos del capital en el ingreso total de un distrito no se correlacionó con el protestantismo entre 1893 y 1910 (Bartels, Kersting y Wolf, 2019).
} 
dito a los miembros de las cooperativas, el fomento del ahorro era un fin en sí mismo para las cajas de ahorros (Trende, 1957), lo que corresponde al énfasis de Weber en la importancia del ahorro para el desarrollo económico. Debido a su propósito específico y al enfoque en sectores más amplios de la población, como sus clientes, argumentamos que las cajas de ahorros son una institución apropiada para estudiar las diferencias regionales del ahorro dentro de Prusia. Además, el Regionalprinzip (principio regional), según el cual no era posible abrir una cuenta si no se vivía en esa región, asegura que los depósitos de ahorro reflejen la propensión a ahorrar de un condado (Lehmann y Wahl, 2017).

Las gráficas 1 y 2 muestran la distribución geográfica del ahorro per cápita en 1880 y 1905, que aumentó notablemente en esos años. En la mayoría de las regiones, salvo en las provincias orientales, el ahorro per cápita superó los 100 marcos en 1905. Además, casi todos los condados tenían al menos una caja de ahorros. ¿Las diferencias de confesión religiosa pueden explicar estas diferencias en el ahorro? La gráfica 3 muestra la distribución geográfica del protestantismo en Prusia en 1900, y sugiere que podría haber alguna relación.

Gráfica 1

Ahorros per cápita, 1880

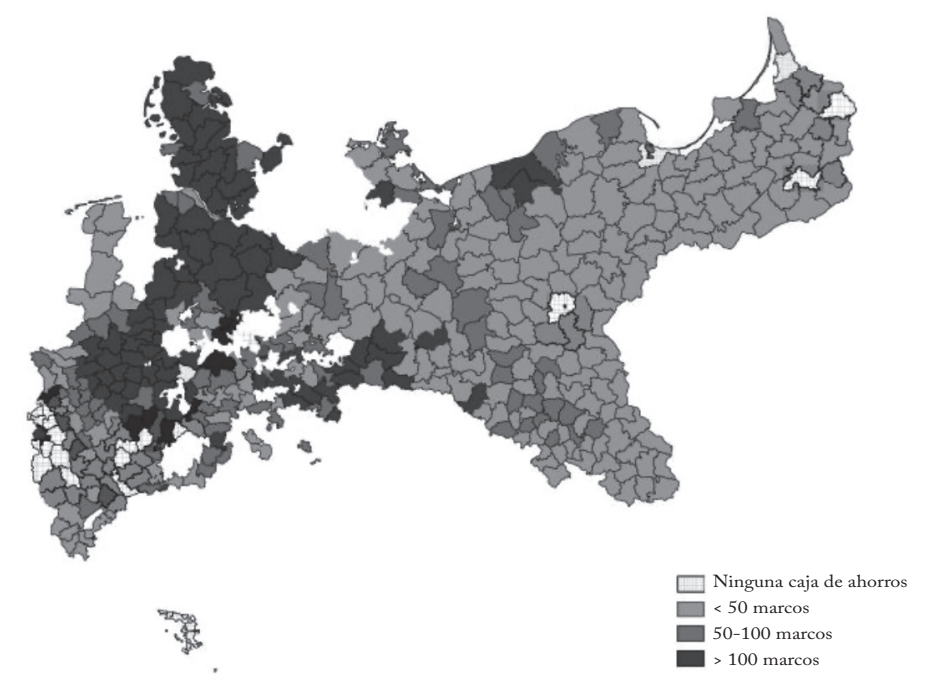

Notas: Los colores más oscuros corresponden a un mayor ahorro per cápita. Los condados de color blanco no tenían una caja de ahorros en 1880 .

Fuente: cuadro B.1 del Apéndice en línea. 
Gráfica 2

Ahorro per cápita, 1905

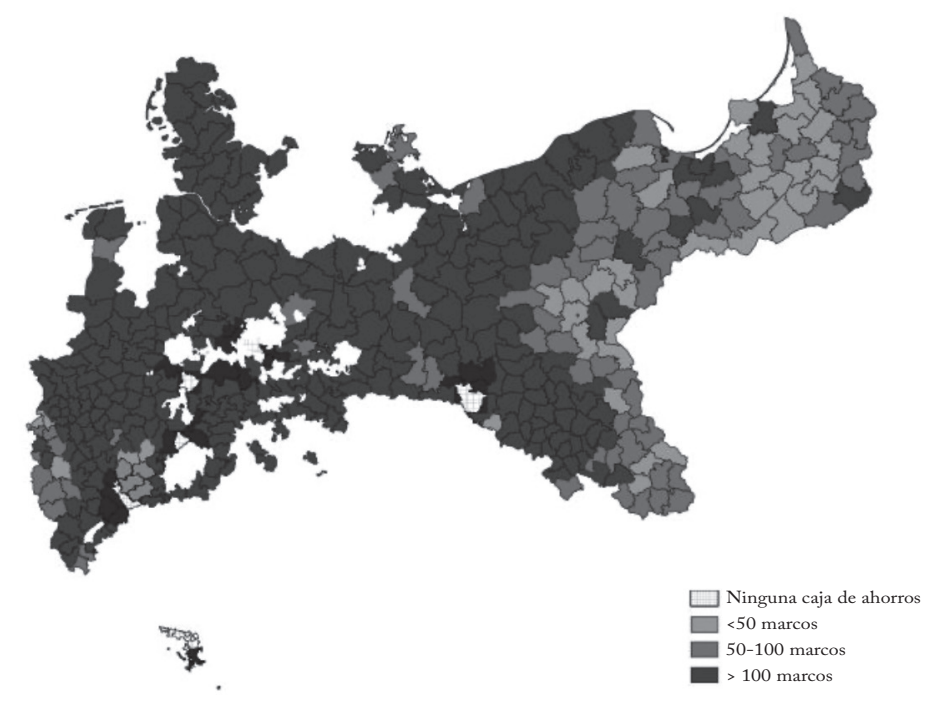

Notas: Los colores más oscuros corresponden a un mayor ahorro per cápita. Fuente: cuadro B.1 del Apéndice en línea.

Los datos del ahorro están disponibles para 1875, 1882, 1888, 1898 y 1904. Ligamos estos datos con el censo disponible más cercano para calcular el ahorro per cápita. Estimamos la siguiente especificación:

$\operatorname{Sav}_{i t}=\alpha 1+\beta 1$ Prot $_{i t}+X_{i t} \gamma_{1}+\varepsilon_{1 i t}$,

donde $S a v_{i t}$ es el ahorro per cápita en el condado $i$ y el año $t, \operatorname{Prot}_{i t}$ la proporción de protestantes, $X_{i t}$ las variables de control que varían en el tiempo, incluida la población urbana, el número de cajas de ahorros, el tamaño del hogar y la proporción de otras religiones además de católicos y protestantes 5 . Preferimos las regresiones MCO agrupadas porque solo hay una variación temporal limitada en nuestra principal variable independiente, la proporción de protestantes. Para más información sobre nuestros datos remitimos al cuadro B.1 del Apéndice en línea. Para controlar el ingreso per cápita, combinamos estadísticas de empleo por sector de cada condado con datos de sala-

${ }^{5}$ Para diferenciar entre las diferentes confesiones protestantes, usamos datos del censo de 1871 (Königlich Statistisches Bureau, 1875), que incluye información de protestantes reformistas y otros protestantes. Menos del 1\% de la población prusiana era reformista. 
rios nacionales por sector. Para tener en cuenta las variaciones de los salarios por sector en los condados, ponderamos nuestra variable de ingresos con datos por condado de los salarios de los jornaleros. $\mathrm{Si}$ no se indica otra cosa, utilizamos errores estándar robustos agrupados a nivel de provincia para tener en cuenta la correlación espacial ${ }^{6}$. E1 cuadro 1 presenta las estadísticas descriptivas.

Gráfica 3

Protestantismo, 1900

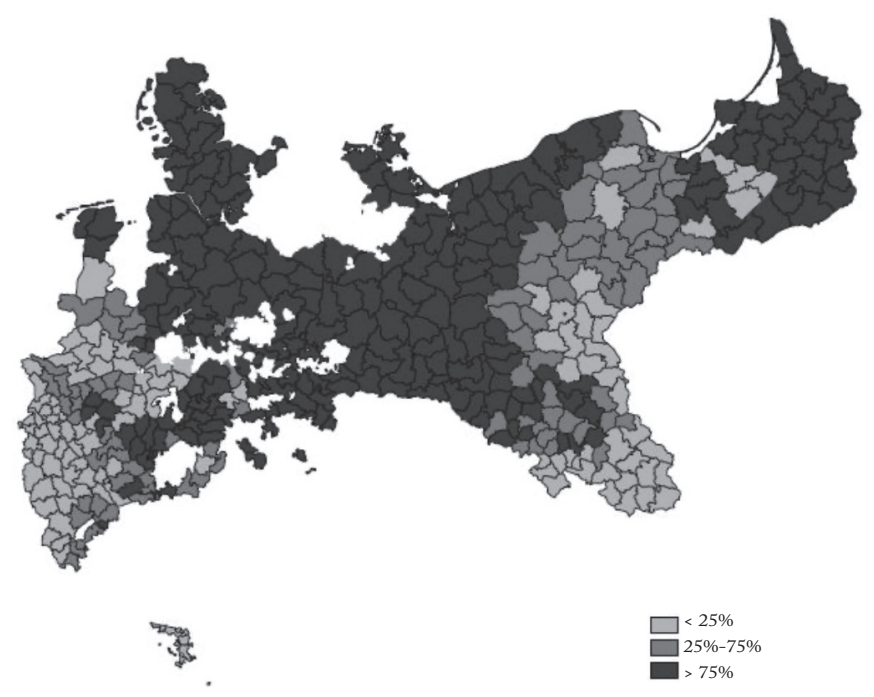

Notas: Los colores más oscuros corresponden a una mayor proporción de protestantes.

Fuente: cuadro B.1 del Apéndice en línea.

Para estimar el efecto del protestantismo en los resultados económicos, necesitamos un instrumento que aísle la variación exógena de la proporción de protestantes en la Prusia del siglo XIX. Como se argumentó en la segunda sección, el mismo Weber (1904/1905) planteó la posibilidad de una causalidad inversa, de variables omitidas o de ambas cosas. No creemos que en nuestro escenario histórico exista un instrumento para el protestantismo a nivel de condado que satisfaga plenamente la restricción de exclusión. Pero consideramos importante limitar en lo posible la influencia de posibles violaciones de la restricción de exclusión. Nuestro enfoque preferido es seguir a Spenkuch (2017) en el uso del elemento idiosincrásico de la confesión religiosa en 1624, el "año normal" de la Paz de Westfalia.

6 Sobre el papel de la correlación espacial, ver Kelly (2019) y Colella et al. (2020). 
Cuadro 1

Estadísticas descriptivas

\begin{tabular}{|c|c|c|c|c|c|}
\hline & 1875 & 1880 & 1890 & 1900 & 1905 \\
\hline \multicolumn{6}{|l|}{ Ahorros } \\
\hline Ahorros per cápita & $\begin{array}{c}42,34 \\
(59,83)\end{array}$ & $\begin{array}{c}64,77 \\
(83,40)\end{array}$ & $\begin{array}{c}94,63 \\
(105,86)\end{array}$ & $\begin{array}{c}153,0 \\
(147,83)\end{array}$ & $\begin{array}{c}206,1 \\
(179,54)\end{array}$ \\
\hline $\begin{array}{l}\text { Ahorros per cápita y cooperativas } \\
\text { de crédito polacas }\end{array}$ & & & & & $\begin{array}{c}207,0 \\
(179,03)\end{array}$ \\
\hline Número de cajas de ahorro & $\begin{array}{l}2.306 \\
(2,59)\end{array}$ & $\begin{array}{l}2.795 \\
(2,89)\end{array}$ & $\begin{array}{l}3.136 \\
(3,16)\end{array}$ & $\begin{array}{l}3.592 \\
(3,70)\end{array}$ & $\begin{array}{l}3.601 \\
(3,15)\end{array}$ \\
\hline \multicolumn{6}{|l|}{ Religión } \\
\hline Proporción de protestantes & $\begin{array}{c}64,61 \\
(37,71)\end{array}$ & $\begin{array}{c}64,46 \\
(37,59)\end{array}$ & $\begin{array}{c}64,03 \\
(37,31)\end{array}$ & $\begin{array}{c}63,72 \\
(36,90)\end{array}$ & $\begin{array}{c}63,44 \\
(36,57)\end{array}$ \\
\hline Proporción de otras religiones & $\begin{array}{l}1.327 \\
(1,30)\end{array}$ & $\begin{array}{l}1.329 \\
(1,23)\end{array}$ & $\begin{array}{l}1.184 \\
(1,09)\end{array}$ & $\begin{array}{l}1.091 \\
(1,00)\end{array}$ & $\begin{array}{l}1.060 \\
(0,97)\end{array}$ \\
\hline \multicolumn{6}{|l|}{ Nación } \\
\hline Proporción de habla alemana & $\begin{array}{c}87,83 \\
(24,62)\end{array}$ & $\begin{array}{c}87,83 \\
(24,62)\end{array}$ & $\begin{array}{c}87,83 \\
(24,62)\end{array}$ & $\begin{array}{c}87,90 \\
(24,18)\end{array}$ & $\begin{array}{c}87,90 \\
(24,18)\end{array}$ \\
\hline \multicolumn{6}{|l|}{ Controles adicionales } \\
\hline Ingreso per cápita & $\begin{array}{c}313,5 \\
(107,11)\end{array}$ & $\begin{array}{c}313,5 \\
(107,11)\end{array}$ & $\begin{array}{c}421,5 \\
(134,93)\end{array}$ & $\begin{array}{c}529,5 \\
(166,95)\end{array}$ & $\begin{array}{c}583,5 \\
(183,86)\end{array}$ \\
\hline Proporción población urbana & $\begin{array}{c}26,96 \\
(18,33)\end{array}$ & $\begin{array}{c}27,86 \\
(18,43)\end{array}$ & $\begin{array}{c}29,23 \\
(19,22)\end{array}$ & $\begin{array}{c}31,11 \\
(19,76)\end{array}$ & $\begin{array}{c}32,12 \\
(19,98)\end{array}$ \\
\hline $\begin{array}{l}\text { Proporción de varones de más de } \\
14 \text { años }\end{array}$ & $\begin{array}{l}68,97 \\
(3,61)\end{array}$ & $\begin{array}{l}65,57 \\
(3,24)\end{array}$ & $\begin{array}{l}64,78 \\
(2,99)\end{array}$ & $\begin{array}{l}64,69 \\
(3,53)\end{array}$ & $\begin{array}{l}65,03 \\
(3,67)\end{array}$ \\
\hline Tamaño promedio del hogar & $\begin{array}{c}4,71 \\
(0,34)\end{array}$ & $\begin{array}{l}4,790 \\
(0,35)\end{array}$ & $\begin{array}{l}4,734 \\
(0,38)\end{array}$ & $\begin{array}{l}4,700 \\
(0,42)\end{array}$ & $\begin{array}{l}4,702 \\
(0,45)\end{array}$ \\
\hline $\mathrm{N}$ & 434 & 434 & 434 & 434 & 434 \\
\hline
\end{tabular}

Notas: Desviación estándar entre paréntesis. Debido a la falta de datos en las estadísticas de empleo antes de 1882, para 1875 tomamos los valores de 1882 . Los resultados no cambian si excluimos a 1875 del análisis. Fuente: Cuadro B.1 del Apéndice en línea.

Todos los signatarios del tratado de paz de 1648 acordaron aceptar la situación confesional que prevalecía en 1624, en particular, no obligar a las personas a cambiar su fe junto con la fe de su gobernante (Kampmann, 2008, p. 176 y ss.). Esta decisión tuvo un fuerte legado histórico (Schilling, 1994, p. 99 y ss.). La idea principal del instrumento de Spenkuch es hacer una regresión entre Protestantes en 1624 a nivel de condado y sus predictores, identificados por Cantoni (2012) (latitud, contribución al Reichsmatrikel, distancia a Wittenberg) y Rubin (2014) (existencia de imprentas) para los condados del antiguo Sacro Imperio Romano (SIR). La distancia a Wittenberg también se usó para construir nuestro VI, porque la distancia al poderoso Estado de Sajonia puede haber cumplido un papel en las interacciones estratégicas de los alrededores (Cantoni, 
2012, pp. 517-518). E1 residuo de esa regresión luego se usa como variable instrumental.

El problema de la causalidad inversa se aborda utilizando un instrumento con un rezago de 200 años. Por construcción, el residuo de esta regresión refleja factores que afectaron la probabilidad de que un condado fuera protestante en 1624 , pero que eran ortogonales a cualquiera de estos controles. Por ejemplo, el residuo podría reflejar el papel de campañas militares, relaciones dinásticas, políticas matrimoniales o accidentes históricos ${ }^{7}$. Con este enfoque abordamos directamente el problema de las posibles violaciones de la restricción de exclusión, con respecto a la influencia de diferencias persistentes de desarrollo económico o de características locales como la etnicidad.

En particular, este enfoque tiene dos ventajas para abordar la etnicidad como factor de confusión. Primera, el VI solo incluye condados que fueron parte del Sacro Imperio Romano, lo que reduce la heterogeneidad étnica de nuestra muestra (pero no la elimina del todo) ${ }^{8}$. Segunda, el control de la distancia a Wittenberg en combinación con una variable de control de la latitud también ayuda a reducir el efecto de la heterogeneidad étnica, porque las diferencias étnicas tienen un patrón geográfico claro (comparar las gráficas 3 y 4). En general, la correlación entre nuestra variable instrumental y la proporción de la población de habla alemana es baja $(0,07)$ y poco significativa.

La alternativa más destacada a la de Spenkuch es la idea de Becker y Woessmann (2009) de usar la distancia a Wittenberg directamente como una VI de la confesión religiosa. Es probable que ese enfoque, igual que cualquier otro instrumento basado en la distancia, viole la restricción de exclusión, dada la geografía de las diferencias étnicas ${ }^{9}$. Por ejemplo, la correlación entre la distancia a Wittenberg y la proporción de población de habla alemana es bastante alta $(-0,35)$ y significativa (tanto para la muestra total como para una muestra limitada al SIR). La correlación es en realidad similar en tamaño a la correlación entre la distancia a Wittenberg y la proporción de protestantes $(-0,37)$.

7 Desde la reforma, la religión fue un factor importante en la política del matrimonio dinástico, ver, p. ej., Duchardt (2001) o Schönpflug (2013).

${ }^{8}$ Por tanto, con nuestro instrumento excluimos varios condados de los distritos orientales de Bromberg, Danzig, Gumbinnen, Königsberg, Köslin, Marienwerder y Posen, así como algunos condados del distrito norte de Schleswig-Holstein.

${ }^{9}$ De los 50 condados más alejados de Wittenberg, 44 se encuentran en las provincias orientales y solo 6 en el suroeste de Prusia. 
Gráfica 4

Lengua materna alemán, 1890

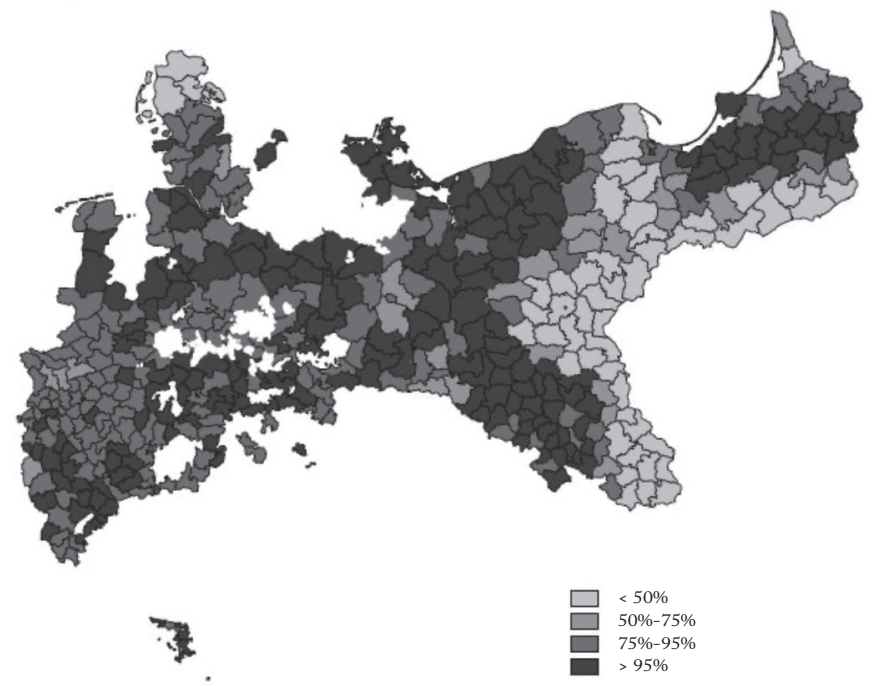

Notas: Los colores más oscuros corresponden a una mayor proporción de hablantes de alemán. Fuente: Cuadro B.1 del Apéndice en línea.

Como ocurre con cualquier VI, no podemos descartar que nuestro enfoque residual aún viole la restricción de exclusión. Pero probamos formalmente si una violación de esa restricción afectaría nuestros resultados, siguiendo a Conley, Hansen y Rossi (2012). La prueba indica que nuestro enfoque es bastante robusto, mientras que la VI alternativa sería muy sensible a una violación de dicha restricción ${ }^{10}$.

Estimamos, entonces, el siguiente modelo de mínimos cuadrados en dos etapas.

Prot $_{i t}=\alpha_{2}+\beta_{2}$ ResiduoProtestante $1624_{i}+X_{i t}{ }^{\prime} \gamma_{2}+\varepsilon_{2 i t}$

$\operatorname{Sav}_{i t}=\alpha_{3}+\beta_{3} \operatorname{Prot}_{i t}+X_{i t}{ }^{\prime} \gamma_{3}+\varepsilon_{3 i t}$

En el siguiente paso probamos el efecto del protestantismo en las tasas de alfabetización, como sugieren Becker y Woessmann (2009).

${ }^{10}$ Siguiendo a Karadja y Prawitz (2019), si permitimos un efecto estandarizado negativo directo de la distancia a Wittenberg de -0,05 en la alfabetización, el coeficiente del protestantismo es poco significativo. El efecto en forma reducida estandarizada de la distancia a Wittenberg es de $-0,37$. Por ello, si solo permitimos ligeras violaciones de la restricción de exclusión, el resultado no es significativo. Si usamos nuestro instrumento preferido, no es así. Podemos permitir un efecto directo de más de la mitad del efecto en forma reducida estandarizada y encontrar efectos significativos. 
Según ellos, Weber se equivocó al sugerir que las actitudes protestantes importaban, pero en cambio el protestantismo ayudó a difundir la Biblia y la capacidad de leer (y escribir). Así, el protestantismo puede haber tenido un efecto en la alfabetización y, por tanto, en el desarrollo económico. A diferencia de nuestros datos de ahorro, las tasas de alfabetización solo están disponibles para una sección transversal en 1871, por ello usamos la siguiente especificación

Lit $_{i}=\alpha_{4}+\beta_{4}$ Prot $_{i}+X_{i}^{\prime} \gamma_{4}+\varepsilon_{42}$

donde Lit $_{i}$ es la proporción de alfabetizados en la población de un condado de 10 años o más, Prot $_{i}$ es la proporción de protestantes en el condado y $X_{i}$ es el mismo conjunto de variables de control demográfico que se usan en Becker y Woessmann (2009) ${ }^{11}$.

Prot $_{i t}=\alpha_{5}+\beta_{5}$ ResiduoProtestante $1624_{i}+X_{i t}^{\prime} \gamma_{5}+\varepsilon_{5 i t}$

Lit $_{i}=\alpha_{6}+\beta_{6}$ Prot $_{i}+X_{i}^{\prime} \gamma_{6}+\varepsilon_{6 i}$

Lo que es más importante, dados los errores potenciales de las regresiones $\mathrm{MCO}$ y VI en nuestro contexto, presentamos evidencia estadística directa de la diferencia en las tasas de alfabetización entre católicos y protestantes dentro de los condados. Utilizamos un cuadro trasversal de alfabetización por religión, proporcionado por Königlich Statistisches Bureau (1875) y digitalizado por Galloway (2007), que hasta ahora ha sido muy olvidado en la literatura ${ }^{12}$.

Después probamos el papel de las diferencias étnicas. Incluimos la proporción de personas cuya lengua materna es el alemán como indicador de las diferencias étnicas. La gráfica 4 muestra la distribución geográfica de la proporción de estas personas. Las minorías se concentraron principalmente en las provincias orientales y en la parte norte cerca de la frontera danesa. Además, hay una minoría polaca más pequeña en el área del Ruhr, los llamados Rubrpolen (polacos del Ruhr). Para la muestra total, esta variable solo está disponible desde 1890. En 1890, el alemán era la lengua materna del 87,8\% de la población de Prusia, el polaco del 9,6\% y otros idiomas (p. ej., el danés) del 2,6\%. Usamos esta información para todos los años y suponemos que no varía en el tiempo ${ }^{13}$. La comparación de las grá-

${ }^{11}$ No hay indicios de que el censo estuviera sesgado hacia los de habla alemana. La pregunta del censo fue si las personas de 10 años o más podían leer y hablar. No preguntó si hablaban alemán (Bureau des Ministeriums des Innern, 1871).

${ }^{12}$ Infortunadamente, no se dispone de datos de alfabetización por nacionalidad étnica.

${ }^{13}$ Para una gran submuestra, hay datos disponibles para 1867. La comparación de los datos de 1867 y 1890 no muestra grandes desviaciones. Por tan- 
ficas 3 y 4 muestra cierta correlación entre la confesión religiosa y el grupo étnico, en especial en la parte oriental de Prusia. Sin embargo, existe una variación considerable en la confesión religiosa en las partes occidentales étnicamente homogéneas de Prusia, por ejemplo, en la provincia del Rin.

Igual que la religión, las diferencias étnicas también pueden ser endógenas. Para evitar este problema, mostramos los resultados incluyendo y excluyendo las provincias orientales de Prusia Oriental y Occidental, Poznan y Silesia. Esto tiene la ventaja de que evitamos una posible multicolinealidad entre confesión religiosa y grupos étnicos en las regiones orientales, que dificultaría esclarecer el efecto entre las dos variables. Las partes restantes de Alemania muestran variaciones muy grandes en la confesión religiosa con minorías étnicas muy pequeñas, lo que debería ser suficiente para identificar un efecto del protestantismo en los resultados económicos.

Habría un problema en nuestros datos de cajas de ahorros si la minoría polaca las considerara instituciones alemanas y prefiriera depositar sus ahorros en otro lugar. No hay evidencia de barreras institucionales para que la minoría polaca accediera a las cajas de ahorros (Trende, 1957, p. 93). Pero esto se ha discutido y hay evidencia de que las cooperativas de crédito polacas competían por los ahorros polacos con un éxito creciente, en especial después del cambio de siglo (Bernhard, 1907, p. 244; ver también Guinnane, 2001). Esto podría sesgar nuestros resultados del efecto de las diferencias étnicas en el ahorro, porque subestimaríamos los ahorros de la comunidad polaca. Para hacerle frente, recopilamos datos de los depósitos de las cooperativas de crédito polacas por condado desde 1905 en las dos provincias de Prusia con mayor proporción de hablantes de polaco (y, en consecuencia, la menor proporción de hablantes de alemán), Poznan y Prusia Occidental. Los datos provienen de los balances de las 225 cooperativas de crédito que eran miembros de la "Asociación de Cooperativas Económicas Polacas de las Provincias de Poznan y Prusia Occidental" publicados por las autoridades prusianas (ver Suesse y Wolf, 2020, Apéndice G $)^{14}$. Puesto que la gran mayoría de los ahorros polacos se depositaban en cooperativas de crédito polacas, como argumentó Bernhard (1907, p. 404), la adición de depósitos de ahorro en cooperativas de crédito polacas a los depósitos de

to, parece plausible usar los datos de 1890 para 1875 y los años siguientes.

${ }^{14}$ No hay datos similares para Prusia Oriental y Silesia, que también tenían altas proporciones de hablantes de polaco, pero podemos mostrar que los resultados son robustos a su exclusión (cuadro 4, columnas 3 y 6). 
ahorro en cajas de ahorros debería corregir ese sesgo potencial. Hay que tener en cuenta que la inclusión de los depósitos de ahorro en las cooperativas de crédito polacas es importante para el ahorro total en Prusia Occidental y Poznan; por ejemplo, en Poznan esta adición aumenta el ahorro total per cápita de 73 a 84 marcos imperiales.

\section{RESULTADOS}

\section{PRUEBA DE LA “INTERPRETACIÓN COMÚN”: MCO}

Empecemos con algunas correlaciones simples entre la proporción de protestantes y la proporción de alemanes con ingresos, ahorros y tasas de alfabetización ${ }^{15}$. Para ellas, hicimos regresiones simples de MCO con ingreso laboral per cápita (1875-1905), ahorro per cápita (1875-1905), ingreso per cápita medido según estadísticas del impuesto de renta (1871) y tasas de alfabetización (1871) como variables de resultado. El cuadro 2 muestra evidencia sugerentes sobre nuestras tres hipótesis. El protestantismo no parece estar fuertemente correlacionado con el ahorro per cápita ni con el ingreso laboral per cápita. Hay una correlación entre protestantismo y tasas de alfabetización, y mucho más fuerte entre proporción de hablantes de alemán y tasas de alfabetización (cuadro 2, panel 4, columna 2). Más en general, encontramos que en todos los resultados el coeficiente estandarizado de la proporción de hablantes de alemán es mayor que el de la proporción de protestantes. Pero la correlación no es causalidad, de modo que debemos recurrir al análisis VI.

\section{EFECTOS CAUSALES SOBRE EL AHORRO}

Para acercarnos lo más posible a la idea central de Weber, primero probamos el comportamiento del ahorro como mecanismo de la “interpretación común”. El cuadro 3 presenta detalles de la relación entre ahorro per cápita y religión de las regresiones $\mathrm{MCO}$ agrupadas y de mínimos cuadrados de dos etapas (MC2E).

Los resultados no apoyan la hipótesis de que los protestantes tienen mayor ahorro per cápita que los católicos debido a una ética de trabajo específica y un estilo de vida ascético. Este "no resultado" es independiente de que incluyamos o no los condados de los distritos orientales (columnas 1 y 2) y de que controlemos el ingreso laboral per cápita (columnas 3 y 4). Como se esperaba, el ingreso laboral per cápita se correlaciona positivamente con el ahorro per cápita. En

${ }^{15}$ Para los archivos de replicación, ver Kersting, Wohnsiedler y Wolf (2020). 
Cuadro 2

Proporción alemana, protestantismo y resultados económicos

\begin{tabular}{|c|c|c|}
\hline & (1) & $(2)$ \\
\hline \multicolumn{3}{|c|}{ Panel 1: Ahorros per cápita, 1875-1905 } \\
\hline Participación de protestantes & $\begin{array}{c}0,042 \\
(0,075)\end{array}$ & $\begin{array}{c}0,021 \\
(0,085)\end{array}$ \\
\hline Proporción de habla alemana & & $\begin{array}{c}0,095 \\
(0,054) \\
\end{array}$ \\
\hline Controles adicionales & Sí & Sí \\
\hline $\mathrm{N}$ & 2.170 & 2.170 \\
\hline $\mathrm{R}^{2}$ & 0,287 & 0,293 \\
\hline \multicolumn{3}{|c|}{ Panel 2: Ingreso laboral per cápita, 1875-1905 } \\
\hline Proporción de protestantes & $\begin{array}{l}-0,054 \\
(0,081)\end{array}$ & $\begin{array}{l}-0,077 \\
(0,077)\end{array}$ \\
\hline Proporción de habla alemana & & $\begin{array}{c}0,112^{*} \\
(0,059)\end{array}$ \\
\hline Controles adicionales & Sí & Sí \\
\hline $\mathrm{N}$ & 2.170 & 2.170 \\
\hline $\mathrm{R}^{2}$ & 0,370 & 0,379 \\
\hline \multicolumn{3}{|c|}{ Panel 3: Ingreso por impuesto de renta per cápita, 1871} \\
\hline Proporción de protestantes & $\begin{array}{c}0,170^{*} \\
(0,091)\end{array}$ & $\begin{array}{c}0,129 \\
(0,095)\end{array}$ \\
\hline Proporción de habla alemana & & $\begin{array}{c}0,244 \\
(0,160)\end{array}$ \\
\hline Controles adicionales & Sí & Sí \\
\hline $\mathrm{N}$ & 426 & 426 \\
\hline $\mathrm{R}^{2}$ & 0,332 & 0,336 \\
\hline \multicolumn{3}{|l|}{ Panel 4: Alfabetización, 1871} \\
\hline Proporción de protestantes & $\begin{array}{c}0,0992^{* * * * *} \\
(0,010)\end{array}$ & $\begin{array}{c}0,0615^{\text {***** }} \\
(0,008)\end{array}$ \\
\hline Proporción de habla alemana & & $\begin{array}{c}0,221^{* * * *} \\
(0,014) \\
\end{array}$ \\
\hline Controles adicionales & Sí & Sí \\
\hline $\mathrm{N}$ & 452 & 452 \\
\hline $\mathrm{R}^{2}$ & 0,737 & 0,831 \\
\hline
\end{tabular}

$* \mathrm{p}<0,1,{ }^{* *} \mathrm{p}<0,05, * * * \mathrm{p}<0,01$.

Notas: Los paneles 1 y 2 muestran los coeficientes beta estandarizados. Los errores estándar van entre paréntesis. Errores estándar robustos agrupados a nivel de provincia. Los controles adicionales incluidos en los paneles 1 y 2 son: número de cajas de ahorros, proporción de hombres trabajadores mayores de 14 años, proporción de población urbana, tamaño medio del hogar, proporción de otras religiones, variable dummy de condados sin caja de ahorros. Los controles adicionales incluidos en los paneles 3 y 4 son: porcentajes de menores de 10 años, de judíos, de mujeres, de nacidos en el municipio y de origen prusiano; tamaño promedio del hogar, tamaño de la población (logaritmo), crecimiento de la población entre 1867 y 1871 (en porcentaje); porcentajes de falta de información de educación, de ciegos, de sordomudos y de enfermos mentales. Fuente: cuadro B.1 del Apéndice en línea.

regresiones adicionales (reportadas en el cuadro A.1 del Apéndice en línea) permitimos efectos heterogéneos para protestantes reformados y otros. No encontramos apoyo para la idea de que los protestantes reformados tengan mayores ahorros per cápita ni mayores tasas de ahorro. En cambio, los protestantes reformados parecen te- 
Cuadro 3

Ahorro per cápita, 1875-1905

\begin{tabular}{|c|c|c|}
\hline & (1) & (2) \\
\hline \multicolumn{3}{|c|}{ Panel 1: Ahorros per cápita, 1875-1905 } \\
\hline Pronorción de protectantes & 0,042 & 0,021 \\
\hline Proporcion de protestantes & $(0,075)$ & $(0,085)$ \\
\hline Proporción de habla alemana & & $\begin{array}{c}0,095 \\
(0,054)\end{array}$ \\
\hline Controles adicionales & Sí & Sí \\
\hline $\mathrm{N}$ & 2.170 & 2.170 \\
\hline $\mathrm{R}^{2}$ & 0,287 & 0,293 \\
\hline \multicolumn{3}{|c|}{ Panel 2: Ingreso laboral per cápita, 1875-1905 } \\
\hline Proporción de protestantes & $\begin{array}{l}-0,054 \\
(0,081)\end{array}$ & $\begin{array}{l}-0,077 \\
(0,077)\end{array}$ \\
\hline Proporción de habla alemana & & $\begin{array}{l}0,112^{*} \\
(0,059)\end{array}$ \\
\hline Controles adicionales & Sí & Sí \\
\hline $\mathrm{N}$ & 2.170 & 2.170 \\
\hline $\mathrm{R}^{2}$ & 0,370 & 0,379 \\
\hline \multicolumn{3}{|c|}{ Panel 3: Ingreso por impuesto sobre la renta per cápita, 1871} \\
\hline Proporción de protestantes & $\begin{array}{c}0,170^{*} \\
(0,091)\end{array}$ & $\begin{array}{c}0,129 \\
(0,095)\end{array}$ \\
\hline Proporción de habla alemana & & $\begin{array}{c}0,244 \\
(0,160) \\
\end{array}$ \\
\hline Controles adicionales & Sí & Sí \\
\hline $\mathrm{N}$ & 426 & 426 \\
\hline $\mathrm{R}^{2}$ & 0,332 & 0,336 \\
\hline \multicolumn{3}{|l|}{ Panel 4: Alfabetización, 1871} \\
\hline Proporción de protestantes & $\begin{array}{c}0,0992^{* * * *} \\
(0,010)\end{array}$ & $\begin{array}{c}0,0615^{* * * * *} \\
(0,008)\end{array}$ \\
\hline Proporción de habla alemana & & $\begin{array}{c}0,221^{* * * *} \\
(0,014)\end{array}$ \\
\hline Controles adicionales & Sí & Sí \\
\hline $\mathrm{N}$ & 452 & 452 \\
\hline $\mathrm{R}^{2}$ & 0,737 & 0,831 \\
\hline
\end{tabular}

${ }^{*} \mathrm{p}<0,1$, ,** $\mathrm{p}<0,05$, ,*** $\mathrm{p}<0,01$.

Notas: Coeficientes beta estandarizados. Los errores estándar van entre paréntesis. Errores estándar robustos agrupados a nivel de provincia. Las provincias orientales incluyen Prusia Oriental y Occidental, Poznan y Silesia. Otros controles incluyen el número de cajas de ahorros, los porcentajes de hombres de más de 14 años que trabajan y de población urbana, el tamaño medio de los hogares, el porcentaje de otras religiones, una variable dummy para los condados sin caja de ahorros.

Fuente: cuadro B.1 del Apéndice en línea.

ner menores ahorros per cápita. Concluimos que debemos rechazar la hipótesis H1, con base en nuestra evidencia de Prusia después de 1871. No hay evidencia de que en la época en que Weber escribía los protestantes ahorraran más que los católicos.

Nuestra lectura de la EP de Weber sugiere que esto no debería sorprendernos. Dado el contexto de nacionalismo y tensiones étnicas creciente, en especial entre alemanes y polacos, podemos pregun- 
tarnos, en cambio, si había diferencias sustanciales en el comportamiento del ahorro entre grupos étnicos. Aquí, un problema es que los datos de las cajas de ahorros podrían subestimar sistemáticamente los ahorros polacos si los polacos realmente empezaron a preferir las cooperativas de crédito polacas para sus depósitos de ahorro, como ya se argumentó. Pero es improbable que este efecto provoque nuestros resultados. Primero porque no encontramos una relación significativa entre ahorro y protestantismo en el cuadro 3 (columna 1 ), aunque podría haber un sesgo contra el ahorro de los polacos, que eran predominantemente católicos. Luego, porque podemos $\mathrm{co}^{-}$ rregir directamente ese sesgo con datos de depósitos de ahorro de cooperativas de crédito polacas, que pudimos encontrar para 1905. En el cuadro 4, hicimos la regresión del cuadro 3 con una variable de control para la proporción de hablantes de alemán (columnas 1 y 2). Vemos que las diferencias étnicas están fuertemente correlacionadas con el comportamiento del ahorro, mientras que las diferencias religiosas no. Si sumamos los depósitos de ahorro de las cooperativas de crédito polacas a nuestra variable dependiente, este resultado se mantiene prácticamente sin cambios (cuadro 4, columnas 4-6).

Como solo tenemos datos del ahorro polaco en los condados de Poznan y Prusia Occidental, mostramos que nuestros resultados principales no cambian cualitativamente si excluimos las otras dos provincias con gran población polaca, Silesia y Prusia Oriental (cuadro 4, columna 3 comparada con la columna 6) ${ }^{16}$. En cada especificación el coeficiente de hablantes de alemán disminuye levemente, pero es alto y significativo ${ }^{17}$. Parece improbable que este efecto se deba a un sesgo polaco contra las cajas de ahorros. En todo caso, los resultados sugieren que las diferencias étnicas estaban fuertemente correlacionadas con los resultados económicos (H3).

${ }^{16}$ La proporción de habla alemana en la población (1890) era del 38,9\% (Poznan), 61,9\% (Prusia Occidental), 76,4\% (Prusia Oriental), 77,1\% (Silesia), 81,2\% (Schleswig-Holstein) y de un $98 \%$ en las provincias restantes de Prusia.

${ }_{17}$ Como nuestro instrumento excluye algunos condados de las provincias orientales, hicimos más regresiones $\mathrm{MCO}$ en el cuadro A.2 del Apéndice en línea. Allí incluimos todos los condados de Prusia, salvo las provincias de Silesia y Prusia Oriental, donde no tenemos datos adicionales sobre el ahorro polaco. Igual que en el cuadro 4, encontramos una fuerte correlación positiva entre proporción de población de habla alemana y ahorro per cápita. El coeficiente de la proporción de habla alemana disminuye levemente, pero es muy significativo una vez controlamos el ahorro polaco. 
Cuadro 4

Ahorro per cápita y diferencias étnicas, 1905

\begin{tabular}{|c|c|c|c|c|c|c|}
\hline & (1) & (2) & (3) & (4) & (5) & (6) \\
\hline Panel 1: MCO & \multicolumn{3}{|c|}{ Var. dep.: Ahorro per cápita } & \multicolumn{3}{|c|}{ +Coop. de crédito polacas } \\
\hline \multirow{2}{*}{ Proporción de protestantes } & 0,067 & 0,069 & 0,081 & 0,067 & 0,069 & 0,081 \\
\hline & $(0,085)$ & $(0,085)$ & $(0,116)$ & $(0,085)$ & $(0,085)$ & $(0,116)$ \\
\hline \multirow{2}{*}{ Proporción de habla alemana } & $0,121^{* * * *}$ & $0,116^{* * *}$ & $0,113^{\text {***** }}$ & $0,121^{* * *}$ & $0,116^{\text {***** }}$ & $0,112^{* * * *}$ \\
\hline & $(0,041)$ & $(0,049)$ & $(0,027)$ & $(0,041)$ & $(0,049)$ & $(0,027)$ \\
\hline \multirow{2}{*}{ Ingreso per cápita } & & 0,033 & $-0,051$ & & 0,032 & $-0,052$ \\
\hline & & $(0,092)$ & $(0,078)$ & & $(0,092)$ & $(0,078)$ \\
\hline Controles adicionales & Sí & Sí & Sí & Sí & Sí & Sí \\
\hline $\mathrm{R}^{2}$ & 0,291 & 0,292 & 0,252 & 0,291 & 0,292 & 0,251 \\
\hline Panel 2: segunda etapa & \multicolumn{3}{|c|}{ Var. dep.: Ahorro per cápita } & \multicolumn{3}{|c|}{+ Coop. de crédito polacas } \\
\hline \multirow{2}{*}{ Proporción de protestantes } & $-0,011$ & $-0,013$ & $-0,069$ & $-0,012$ & $-0,014$ & $-0,070$ \\
\hline & $(0,107)$ & $(0,103)$ & $(0,181)$ & $(0,107)$ & $(0,104)$ & $(0,181)$ \\
\hline \multirow{2}{*}{ Proporción de habla alemana } & $0,129^{* *}$ & $0,126^{* * *}$ & $0,129^{* * * *}$ & $0,128^{* *}$ & $0,125^{* *}$ & $0,128^{* * *}$ \\
\hline & $(0,041)$ & $(0,050)$ & $(0,035)$ & $(0,040)$ & $(0,050)$ & $(0,035)$ \\
\hline \multirow{2}{*}{ Ingreso per cápita } & & 0,023 & $-0,080$ & & 0,023 & $-0,080$ \\
\hline & & $(0,095)$ & $(0,096)$ & & $(0,095)$ & $(0,096)$ \\
\hline Panel 3: primera etapa & \multicolumn{6}{|c|}{ Variable dependiente: Protestanismo } \\
\hline \multirow{2}{*}{ Decisión residual 1624} & $0,407^{\text {**** }}$ & $0,414^{* * * *}$ & $0,262^{\text {***** }}$ & $0,407^{* * * *}$ & $0,414^{* * * *}$ & $0,262^{* * * *}$ \\
\hline & $(0,096)$ & $(0,090)$ & $(0,063)$ & $(0,096)$ & $(0,090)$ & $(0,063)$ \\
\hline \multirow{2}{*}{ Proporción de habla alemana } & 0,065 & 0,087 & 0,063 & 0,065 & 0,087 & 0,063 \\
\hline & $(0,104)$ & $(0,094)$ & $(0,067)$ & $(0,104)$ & $(0,094)$ & $(0,067)$ \\
\hline \multirow{2}{*}{ Ingreso per cápita } & & $-0,148$ & $-0,223$ & & $-0,148$ & $-0,223$ \\
\hline & & $(0,159)$ & $(0,138)$ & & $(0,159)$ & $(0,138)$ \\
\hline $\mathrm{R}^{2}$ & 0,331 & 0,343 & 0,424 & 0,331 & 0,343 & 0,424 \\
\hline Incluyendo Silesia y Prusia Oriental & Sí & Sí & No & Sí & Sí & No \\
\hline Controles adicionales & Sí & Sí & Sí & Sí & Sí & Sí \\
\hline F- instrumentos estadísticos excluidos & 17,85 & 21,01 & 17,20 & 17,85 & 21,01 & 17,20 \\
\hline $\mathrm{N}$ & 366 & 366 & 281 & 366 & 366 & 281 \\
\hline
\end{tabular}

* $\mathrm{p}<0,1,{ }^{* *} \mathrm{p}<0,05, * * * \mathrm{p}<0,01$.

Notas: Coeficientes beta estandarizados. Errores estándar entre paréntesis. Errores estándar robustos agrupados a nivel de provincia. Otros controles incluyen el número de cajas de ahorros, los porcentaje de hombres más de 14 años que trabajan y de población urbana, el tamaño medio de los hogares, el porcentaje de otras religiones, una variable dummy para los condados sin cajas de ahorro. En las columnas (1) y (2) incluimos el ahorro per cápita de las cajas de ahorros, y en las columnas (3) a (5) sumamos los depósitos de las cooperativas de crédito polacas.

Fuente: cuadro B.1 del Apéndice en línea.

\section{EFECTOS CAUSALES EN LAS TASAS DE ALFABETIZACIÓN}

Aunque en Prusia de finales del siglo XIX no hay evidencia de que los protestantes tuvieran mayor ahorro per cápita, podría ser que el protestantismo importara para el desarrollo económico mediante 
otro mecanismo, tal como las tasas de alfabetización como sostienen Becker y Woessmann (2009).

$\mathrm{E} 1$ primer paso para probar la hipótesis $\mathrm{H} 2$ fue analizar un cuadro transversal que incluye información sobre alfabetización por religión desde 1871. Esta evidencia es esencial porque muestra directamente que las tasas de alfabetización difieren entre protestantes y católicos dentro de los condados. Es sorprendente que esto haya sido muy ignorado en la literatura empírica existente. La gráfica 5 representa la proporción de protestantes y la proporción de protestantes alfabetizados en alfabetizados. Cada punto representa un condado. $\mathrm{La}$ intuición es la siguiente: un punto a la derecha de la línea de 45 grados indica que los protestantes tienen un nivel de alfabetización más que proporcional en este condado. El panel (a) muestra que existe alguna evidencia de que los protestantes son proporcionalmente más alfabetizados. Sin embargo, la mayoría de los condados en los que los protestantes tienen un nivel de alfabetización más que proporcional se encuentran en la parte oriental de Prusia con una gran población de habla polaca, como se ve en el panel (b). En los condados que excluyen las provincias orientales, la relación entre protestantes alfabetizados y protestantes sigue muy de cerca la línea de 45 grados como se muestra en el panel (c).

La diferencia en las tasas de alfabetización de católicos y protestantes dentro de los condados es de apenas 1,05 puntos porcentuales para toda la muestra. Una vez excluimos las provincias orientales, esta diferencia se reduce a 0,14 puntos porcentuales. Otra manera de ilustrar esto es mostrar la diferencia en la proporción de protestantes alfabetizados entre alfabetizados y la proporción de protestantes en un mapa: la gráfica 6 muestra que los condados con una alfabetización más que proporcional de protestantes se ubican exclusivamente en la parte oriental de Prusia ${ }^{18}$.

El cuadro 5 muestra los resultados de un enfoque MCO y VI. Para comparar nuestros resultados sobre ahorro con los de la literatura anterior, nos centramos de nuevo en las tasas de alfabetización promedio por condado. Para empezar, los resultados MCO sugieren un efecto pequeño pero significativo del protestantismo en la alfabetización promedio por condado (columna 1). Las tasas son aún más pequeñas si excluimos las provincias orientales (columna 2), o si las incluimos pero controlamos la proporción de hablantes de alemán

18 En el resto de Prusia solo hay pocos condados donde esta diferencia es mayor de 1 punto porcentual: los condados de Moers, Rees, Gladbach y Wiedenbrück. Pero incluso esta diferencia no es significativa. 
Gráfica 5

Alfabetización y protestantismo, 1871

(a) Todos los condados

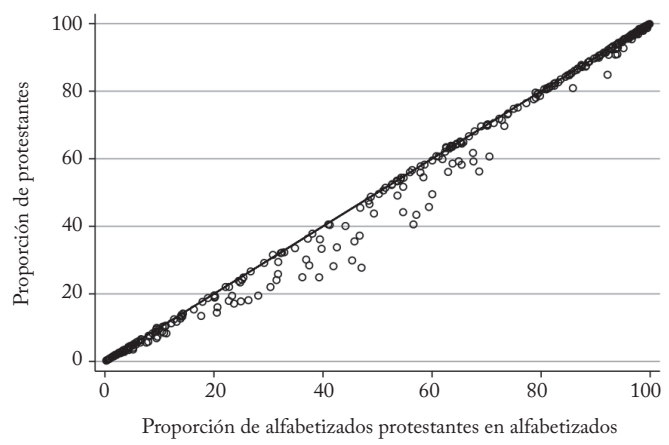

(b) Provincias del Este

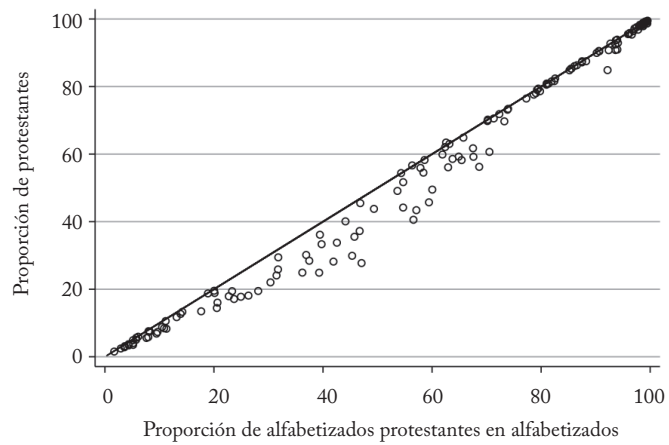

(c) Provincias occidentales

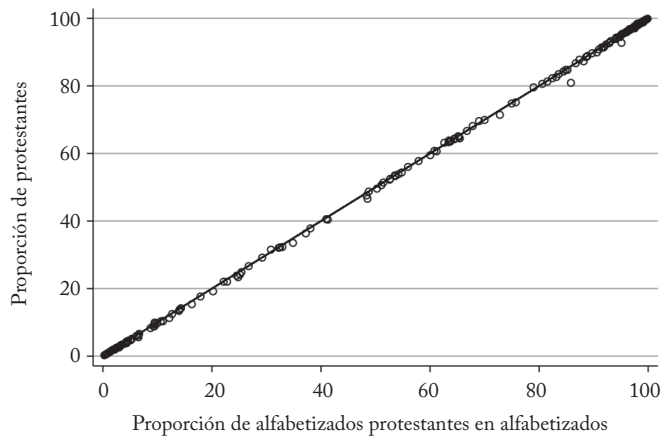

Notas: Cada punto corresponde a un condado. Interpretación: los protestantes tienen un nivel de alfabetización excesivo en los condados a la derecha de la línea de 45 grados. Provincias orientales: Poznan, Silesia, Prusia occidental y oriental.

Fuente: Cuadro B.1 del Apéndice en línea. 
(columna 3), y mucho más pequeñas que las de los hablantes de alemán. Sin embargo, el coeficiente MCO sigue siendo estadísticamente significativo. Una posible razón podría ser la tradición educativa protestante específica del condado, que pudo haber tenido efectos positivos en los católicos, como sugieren Becker y Woessmann $(2009)^{19}$. Alternativamente, el resultado MCO podría reflejar una causalidad inversa, de la alfabetización al protestantismo, o un problema de variables omitidas a nivel de condado, como se discutió en la cuarta sección. Para abordar esto, necesitamos un instrumento y volver a usar la VI de Spenkuch. Nuestros resultados concuerdan con la evidencia del cuadro trasversal que se presenta en las gráficas 5 y 6 . No encontramos ningún efecto positivo significativo del protestantismo en las tasas de alfabetización (cuadro 5, panel 2, columnas 1 a 3). Además, probamos la idea de que el protestantismo afecta los resultados económicos con la alfabetización como variable mediadora, pero no encontramos mucho apoyo para esa idea (ver Apéndice $\mathrm{C}$ en línea $)^{20}$.

En el cuadro 5 (columna 3), vemos que el efecto de la proporción de hablantes de alemán es grande y muy significativo. Un aumento del $1 \%$ en la proporción de población cuya lengua materna es el alemán está asocia a un aumento de 0,2 puntos porcentuales en la alfabetización. Dado el tamaño de este efecto, las diferencias étnicas deberían ser una variable de control para la "interpretación común", en particular para la Alemania del siglo XIX. En conjunto, nuestros resultados muestran un fuerte apoyo para $\mathrm{H} 3$, pero no para $\mathrm{H} 1 \mathrm{ni}$ $\mathrm{H} 2$.

19 En el cuadro A.6 del Apéndice en línea, usamos los datos del cuadro transversal para probar los efectos indirectos del protestantismo en Becker y Wössmann (2009). Con este fin, usamos la alfabetización entre católicos por condado como variable dependiente y probamos si la proporción de protestantes en un condado tiene un efecto positivo. La regresión MCO (panel 1) no sugiere ningún efecto. Una regresión IV con la distancia a Wittenberg sugiere un efecto positivo débilmente significativo, pero solo si restringimos la muestra a la del SIR. Usando el residuo de 1624 como instrumento, no encontramos ningún efecto de la proporción de protestantes en las tasas de alfabetización entre católicos.

${ }^{20}$ En el Apéndice $C$ en línea comparamos nuestros resultados de manera más directa con los de Becker y Woessmann (2009). Allí replicamos sus resultados y mostramos que el control de los hablantes de alemán, los cambios de muestra y el uso de la distancia a Wittenberg como VI llevan a resultados diferentes. 
Cuadro 5

Efecto del protestantismo en la alfabetización, 1871

\begin{tabular}{|c|c|c|c|}
\hline & (1) & (2) & (3) \\
\hline Panel 1: MCO & \multicolumn{3}{|c|}{ Dep. var. Literatura } \\
\hline Proporción de protestantes & $\begin{array}{l}0,057^{* * * *} \\
(0,009)\end{array}$ & $\begin{array}{l}0,033^{* * *} \\
(0,013)\end{array}$ & $\begin{array}{l}0,040^{* * * *} \\
(0,012)\end{array}$ \\
\hline Proporción de habla alemana & & & $\begin{array}{l}0,213^{* * * *} \\
(0,036)\end{array}$ \\
\hline $\mathrm{R}^{2}$ & 0,610 & 0,431 & 0,735 \\
\hline Panel 2: segunda etapa & \multicolumn{3}{|c|}{ Dep. var. Literatura } \\
\hline Proporción de protestantes & $\begin{array}{c}0,030 \\
(0,018)\end{array}$ & $\begin{array}{c}0,031 \\
(0,017)\end{array}$ & $\begin{array}{c}0,020 \\
(0,015)\end{array}$ \\
\hline Proporción de habla alemana & & & $\begin{array}{c}0,221^{* * * *} \\
(0,036)\end{array}$ \\
\hline Panel 3: primera etapa & \multicolumn{3}{|c|}{ Dep. var. Protestanismo } \\
\hline Decisión residual 1624 & $\begin{array}{c}46,088^{\text {***k }} \\
(4,227)\end{array}$ & $\begin{array}{c}43,094^{* * * *} \\
(3,277)\end{array}$ & $\begin{array}{l}45,369^{* * * *} \\
(2,866)\end{array}$ \\
\hline Proporción de habla alemana & & & $\begin{array}{c}0,327^{* * * *} \\
(0,144) \\
\end{array}$ \\
\hline $\mathrm{R}^{2}$ & 0,474 & 0,599 & 0,489 \\
\hline Incluyendo Silesia y Prusia Oriental & Sí & No & Sí \\
\hline Controles adicionales & Sí & Sí & Sí \\
\hline F- instrumentos estadísticos excluidos & 246,34 & 172,95 & 250,58 \\
\hline $\mathrm{N}$ & 378 & 280 & 378 \\
\hline
\end{tabular}

${ }^{*} \mathrm{p}<0,1,{ }^{* *} \mathrm{p}<0,05,{ }^{* * * *} \mathrm{p}<0,01$.

Notas: Notas: Errores estándar entre paréntesis. Errores estándar robustos agrupados a nivel de provincia. Las provincias orientales incluyen Prusia Oriental y Occidental, Poznan y Silesia. Controles adicionales: porcentaje por debajo del 10, porcentaje de judíos, porcentaje de mujeres, porcentaje de nacidos en el municipio, porcentaje de origen prusiano, tamaño promedio del hogar, tamaño de la población (logaritmo), crecimiento de la población de 1867 a 1871 (en porcentaje), porcentaje de información educativa faltante, porcentaje de personas ciegas, porcentaje de sordomudos, porcentaje de locos.

Fuente: cuadro B.1 del Apéndice en línea.

\section{¿POR QUÉ IMPORTAN LAS DIFERENCIAS ÉTNICAS?}

Nuestro resultado del papel de las diferencias étnicas en los resultados económicos requiere una explicación. Es improbable que la etnicidad capte diferencias profundas en las actitudes entre alemanes, polacos y otros grupos étnicos, como sostiene Weber en su CI de 1895. Sugerimos, en cambio, que los efectos podrían resultar de la interacción entre alemanes y polacos. En particular, presentamos evidencia sugerente del papel de la discriminación contra la minoría polaca por parte de la mayoría alemana y de la construcción de instituciones polacas como reacción a esa discriminación. Está más allá del alcance de este artículo analizar esto en detalle, pero se debería abordar en posteriores investigaciones. 


\section{Gráfica 6}

Diferencia porcentual entre protestantes alfabetizados y protestantes y porcentaje de protestantes, 1871

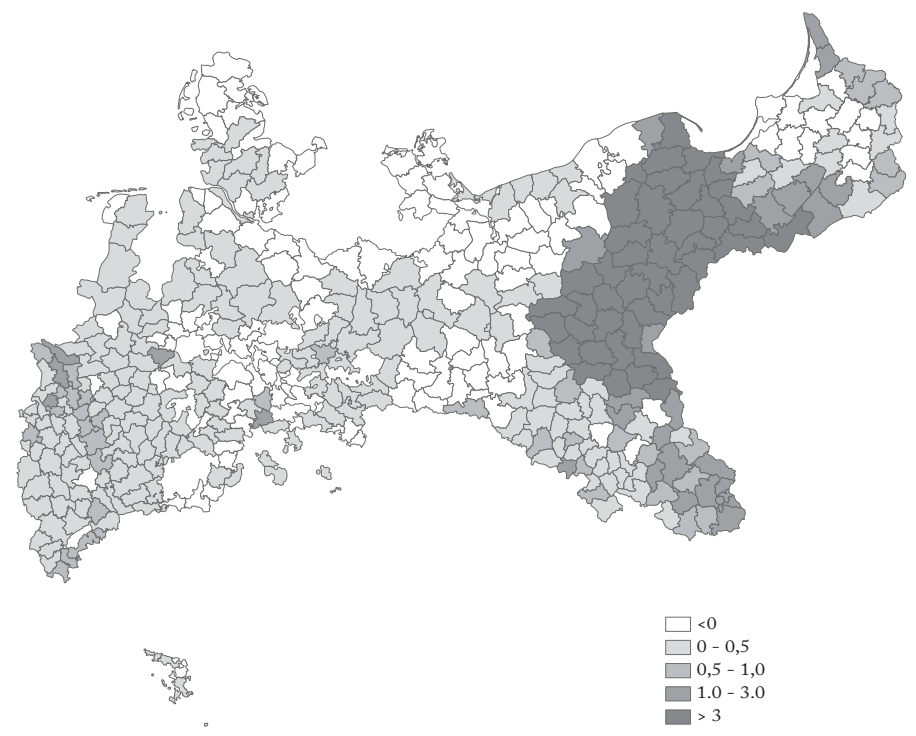

Notas: El mapa muestra la diferencia entre la proporción de protestantes y la proporción de protestantes alfabetizados entre alfabetizados en cada condado. Cuanto más proporcionalmente alfabetizados son los protestantes, más oscuro es el color del condado.

Fuente: cuadro B.1 del Apéndice en línea.

Como mostramos en la sección sobre el contexto histórico, las tensiones entre nacionalidades aumentaron en el Imperio Alemán después de su fundación. Un aspecto $-\mathrm{O}$, mejor, el principal- de estas tensiones era la discriminación contra la gran minoría polaca en la política educativa. El gobierno prusiano ya había aplicado políticas discriminatorias contra los polacos antes de 1870, en especial políticas lingüísticas restrictivas después de 1848 (Gessinger, 1991, p. 118 y ss.). Después de 1870, el gobierno alemán proporcionó incentivos monetarios (1lamados Ostmarkenzulage) para que profesores alemanes trabajaran en las provincias orientales, los cuales atrajeron a más profesores nacionalistas con la misión de "germanizar" el Este (Lamberti, 1989). La evidencia anecdótica sugiere que esto tuvo efectos sorprendentes. Por ejemplo, en Poznan, la ciudad polaca más grande del Imperio, la escuela primaria católica más prestigiosa (la escuela de Santa María Magdalena) tenía 24 profesores polacos en 1870, solo 3 en 1890 y 2 en 1912 (Molik, 1998, p. 22). Otro resultado de esta política discriminatoria fue que los gastos por alumno eran menores en las provincias orientales (Lamberti, 1989). Las 
regiones de Prusia con mayor polarización lingüística, es decir, las provincias orientales, tendían a gastar menos en el sistema educativo descentralizado (Cinnirella y Schueler, 2016). Además, hay pruebas de que las escuelas de las provincias orientales con mayor proporción de alumnos de habla alemana eran las preferidas en términos de recursos (Lamberti, 1989). Otro aspecto importante de esto es la educación superior. Pese a décadas de discusión sobre el tema, que comenzó ya en 1815 y se intensificó después de 1871, no había ninguna universidad en estas provincias, en contraste con la parte austriaca de Polonia (con las universidades de Cracovia y Lwow, fundadas en 1364 y 1661, respectivamente), y la parte rusa (con la universidad de Varsovia, inaugurada en 1815 y cerrada en 1869). Los hablantes de polaco tenían que ir a la universidad en una de las provincias alemanas y estudiar en alemán. Según Schutte (2008), la renuencia alemana a abrir una universidad en las provincias polacas se debía al temor de la mayoría alemana de que una mejor educación pudiera equipar a la minoría polaca con instrumentos más efectivos para resistir la discriminación y construir su propia nación. La apertura en 1903 de una Real Academia en Poznan que cumplía algunas funciones limitadas de una universidad (en idioma alemán) estuvo acompañada de un acalorado debate. Solo en 1919, después de que Polonia se restableció como estado, la Academia se convirtió en una universidad completa, que podía satisfacer las necesidades de la sociedad polaca.

Esta discriminación educativa probablemente tuvo efectos directos en los logros educativos y la formación de capital humano. En la medida en que esa discriminación empezó antes de 1871, en el ámbito de la política lingüística y la educación superior, por ejemplo, podría ayudar a explicar las diferencias en las tasas de alfabetización alrededor de 1871 (ver Knabe, 2000, p. 162 y ss.). También tendría efectos en las ganancias y los ingresos, pero no necesariamente en las tasas de ahorro, a menos que afectara más los ahorros que los ingresos. Como sugiere la literatura sobre educación financiera, es probable que sea así (Lusardi y Mitchell, 2011), pero requeriría una investigación.

La creciente segregación nacional en el mercado laboral también podría ayudar a explicar la diferencia en los resultados económicos. La distribución ocupacional se puede usar como indicador del estatus de los diferentes grupos en una sociedad, como muestran Hsieh et al. (2013) en Estados Unidos. Estos autores también muestran 
que las fricciones en los mercados laborales, que se pueden deber a la discriminación, pueden llevar a una mala asignación sistemática del talento con implicaciones de gran alcance para el desarrollo económico. Según Hagen (1981), había diferencias notables en la estructura ocupacional entre alemanes y polacos. La proporción entre alemanes y polacos de las diferentes ocupaciones en la provincia de Poznan era: médicos, 3 a 1; veterinarios, 8 a 1; boticarios, 3 a 1; abogados y notarios, 4 a 1 ; y empleados de ferrocarriles y oficinas postales, 19 a 1 . Puesto que la proporción de polacos en Poznan era de casi el 50\%, estas cifras muestran una división nacional muy clara en el mercado laboral. El estadístico de la época Max Broesike (1909) presenta más evidencia de la fuerte segregación entre polacos y alemanes en el mercado laboral de la provincia de Silesia: los polacos estaban subrepresentados en el sector industrial y especialmente en los servicios públicos. En cambio, se concentraban en el sector agrícola. Desde la década de 1860, los rangos más altos de la administración pública de Ostelbien estaban dominados casi exclusivamente por alemanes (Molik, 1998). Entre las profesiones académicas, la medicina era la más atractiva para la minoría polaca, debido también a la relativa independencia de la intervención estatal. E1 número de médicos polacos en la provincia de Poznan aumentó en términos absolutos entre 1872 y 1912, y también en relación con el número de médicos alemanes (ibíd.). Pero las diferencias siguieron siendo enormes. El cuadro A.3 del Apéndice en línea presenta evidencia detallada de los médicos de cada distrito en la provincia de Poznan en 1907 y muestra marcadas diferencias entre la proporción de médicos polacos y la proporción de población de habla polaca. En resumen, hay evidencia que sugiere que la discriminación antipolaca es una posible explicación de las grandes diferencias en los resultados económicos entre alemanes y polacos. Aquí no podemos fundamentar estas ideas, pero pueden ser tema fructífero de futura investigación.

\section{CONCLUSIÓN}

Revisamos la evidencia de la EP de Max Weber en el contexto en que escribió: el Imperio Alemán antes de 1914. En palabras de Robert Margo, este es un ejemplo de por qué "poner el contexto en frente y en el centro es la esencia de la historia económica, su contribución a la economía per se" (Margo, 2017, p. 37). Mostramos que una mala interpretación de este contexto puede llevar fácilmente a omitir los 
principales factores de la evidencia, y a especificaciones econométricas erróneas. Nuestro principal argumento es que la "interpretación común” de la EP de Weber ha olvidado medida su enfoque del comportamiento de ahorro y su nacionalismo antipolaco. Primero, probamos la sugerencia de Weber de que el protestantismo importaba debido a una "compulsión ascética de salvar". Usando datos de la Prusia de finales del siglo XIX podemos rechazar claramente esta hipótesis. Ni en MCO simples ni en regresiones VI, ni en submuestras encontramos que los protestantes ahorraban más que los católicos (cuadros 3 y 4). Pero hay evidencia de que el comportamiento del ahorro difería entre alemanes y polacos (cuadro 4). Luego probamos la hipótesis de que el protestantismo importaba a través de las diferencias en las tasas de alfabetización. Usando evidencia estadística directa mostramos que esas diferencias no eran significativas en las provincias de Prusia de habla predominantemente alemana y que solo importaban en el Este, en regiones de gran minoría polaca (gráfica 5). Confirmamos estos resultados mediante regresiones $\mathrm{MCO}$ e VI (cuadro 5). Tomados en conjunto, los resultados económicos en la Prusia de finales del siglo XIX diferían mucho más entre grupos étnicos que entre grupos religiosos.

Esta nueva evidencia empírica concuerda con la mayor parte de la literatura histórica, que subraya el papel cada vez más importante del conflicto nacional entre alemanes y minorías nacionales hacia fines del siglo XIX, mientras que las tensiones entre protestantes y católicos disminuyeron después del final de la Kulturkampf. Las autoridades alemanas utilizaron su poder, en el ámbito de la política educativa y en otros campos, cada vez más orientado contra la minoría polaca. Presentamos e videncia tentativa de que los polacos eran discriminados en las políticas educativas y en los mercados laborales. También mostramos que el surgimiento de estructuras paralelas polacas, como las cooperativas de crédito polacas utilizadas como sustitutos de las cajas de ahorros, es relevante en nuestro contexto. En otro nivel, encontramos que esto concuerda con una lectura crítica de la EP de Weber, la cual se debe entender en su contexto histórico. Weber era un ardiente nacionalista alemán, y sería ingenuo considerar la EP solo como un intento de explicar los orígenes del capitalismo. Es, sin duda, un texto fundacional de la sociología y la economía cultural. Pero más allá de ello, se debe entender como una intervención política cuyo objetivo era hacer un "llamado" a la clase política. No queremos descartar una interpretación más abstracta 
del escrito de Weber desde la perspectiva de la economía empírica. Esta puede ser estimulante y producir conocimientos valiosos. Pero nuestra evidencia advierte que la "interpretación común” de la EP de Weber debe tener en cuenta el nacionalismo y las diferencias étnicas, en el contexto de la Alemania del siglo XIX o en otros lugares.

\section{REFERENCIAS BIBLIOGRÁFICAS}

Acemoglu, D. (2009). Introduction to modern economic growth. Princeton: Princeton University Press.

Alaoui, L. y Sandroni, A. (2018). Predestination and the protestant ethic. Journal of the European Economic Association, 16(1), 45-76.

Barbalet, J. M. (2001). Weber's Inaugural Lecture and its place in his sociology. Journal of Classical Sociology, 1(2), 147-170.

Barbalet, J. M. (2008). Weber, passion and profits: The Protestant ethic and the spirit of capitalism in context. Cambridge: Cambridge University Press.

Barro, R. J. y McCleary, R. M. (2003). Religion and economic growth across countries. American Sociological Review, 68(5), 760-781.

Bartels, C. (2019). Top incomes in Germany, 1871-2014. Journal of Economic History, 79(3), 669-707.

Bartels, C, Kersting, F. y Wolf, N. (2019). Testing Marx: Income inequality, market concentration and voting in late 19th Century Germany. Stone center on Socio-Economic Inequality, Working Paper Series 32.

Becker, G. (1997). Replication and reanalysis of Offenbacher's school enrollment study: Implication for the Weber and Merton theses. Journal for the Scientific Study of Religion, 36(4), 483-495.

Becker, S. O., Cinnirella, F., Hornung, E. et al. (2014). iPEHD - The IFO Prussian Economic History Database. Historical Methods: A Journal of Quantitative and Interdisciplinary History, 47(2), 57-66.

Becker, S. O., Pfaff, S. y Rubin, J. (2016). Causes and consequences of the Protestant Reformation. Explorations in Economic History, 62, 1-25.

Becker, S. O. y Woessmann, L. (2009). Was Weber wrong? A human capital theory of Protestant economic history. Quarterly Journal of Economics, 124(2), 531-596.

Belzyt, L. (1998). Sprachliche Minderheiten im preußischen Staat 1815-1914. Marburg: Verlag Herder-Institut.

Bénabou, R. y Tirole, J. (2004). Willpower and personal rules. Journal of Political Economy, 112(4), 848-486.

Bénabou, R. y Tirole, J. (2006). Incentives and prosocial behavior. American Economic Review, 96(5), 1652-1678.

Bénabou, R. y Tirole, J. (2011) Identity, morals, and taboos: Beliefs as assets. Quarterly Journal of Economics, 126(2), 805-855.

Bernhard, L. (1907). Die Polenfrage: Das polnische Gemeinwesen im preußischen Staat. Leipzig: Duncker \& Humblot.

Broadberry, S. N. y Burhop, C. (2007). Comparative productivity in British and German manufacturing before World War II: Reconciling direct benchmark estimates and time series projections. Journal of Economic History, 67(2), 315-349. 
Broesike, M. (1909). Die oberschlesischen Polen. Zeitschrift des Königlich Preussischen Statistischen Landesamts, 49(1909), 25-62.

Bureau des Ministeriums des Innern. (1871). Ministerial-Blatt für die gesammte innere Verwaltung in den Königlich Preußischen Staaten, 32. Jahrgang. Berlín: Verlag des Kaiserlichen Post-Zeitungs-Amts.

Cantoni, D. (2012). Adopting a new religion: The case of Protestantism in 16th Century Germany. Economic Journal, 122(560), 502-531.

Cantoni, D. (2015). The economic effects of the Protestant Reformation. Journal of the European Economic Association, 13(4), 561-598.

Cantoni, D., Dittmar, J. y Yuchtman, N. (2018). Religious competition and reallocation: The political economy of secularization in the Protestant Reformation. Quarterly Journal of Economics, 133(4), 2037-2096.

Cinnirella, F. y Schueler, R. M. (2016). The cost of decentralization: Linguistic polarization and the provision of education. CESifo working paper 5894, Múnich.

Colella, F., Lalive, R., Sakalli, S. O. et al. (2020). Inference with arbitrary clustering. HEC University of Lausanne: mimeo.

Conley, T. G., Hansen, C. B. y Rossi, P. E. (2012). Plausibly exogenous. Review of Economics and Statistics, 94(1), 260-272.

Delacroix, J. y Nielsen, F. (2001). The beloved myth: Protestantism and the rise of industrial capitalism in Nineteenth-Century Europe. Social Forces, 80(2), 509-553.

Doepke, M. y Zilibotti F. (2008). Occupational choice and the spirit of capitalism. Quarterly Journal of Economics, 123(2), 747-793.

Dohmen, T., Enke, B., Falk, A. et al. (2018). Patience and comparative development. University of Bonn: mimeo.

Duchhardt, H. (2001). Die dynastische Heirat als politisches Signal. En E. Bialek y J. Szafarz (eds.), Hochzeit als ritus und casus (pp. 67-70). Wroclaw: Oficyna Wydawnicza.

Galloway, P. R. (2007). Galloway Prussia database 1861 to 1914, [www. patrickgalloway.com].

Gessinger, J. (1991). Sprachenpolitik gegenüber fremdsprachiger Bevö1kerung in Preußen im 19. Jahrhundert. En R. Wimmer (ed.), Das 19. Jahrhundert. Sprachgeschichtliche Wurzeln des heutigen Deutsch (pp. 106-124. Berlín: De Gruyter.

Graf, F. W. (1995). The German theological sources and Protestant Church politics. En H. Lehmann y G. Roth (eds.), Weber's Protestant Ethic: Origins, evidence, contexts (pp. 27-50). Cambridge: Cambridge University Press, 1995.

Grant, O. (2005). Migration and inequality in Germany 1870-1913. Oxford: Oxford University Press.

Guinnane, T. W. (2001). Cooperatives as information machines: German rural credit cooperatives, 1883-1914. Journal of Economic History, 61(2), 366-389.

Hagen, W. W. (1981). Germans, Poles, and Jerws: The Nationality Conflict in the Prussian East, 1772-1914. Chicago: University of Chicago Press.

Hoffmann, W. G. (1965). Das Wachstum der deutschen Wirtschaft seit der Mitte des 19. Jahrbunderts. Berlín: Springer. 
Hornung, E. Railroads and Growth in Prussia (2015). Journal of the European Economic Association,13(4), 699-736.

Hsieh, C.-T., Hurst, E., Jones, C. I. y Klenow, P. J. (2013). The allocation of talent and U.S economic growth. NBER working paper 18693, Cambridge, Mass.

Iannaccone, L. R. (1998). Introduction to the economics of religion. Journal of Economic Literature, 36(3) 1465-1495.

Kaiserliches Statistisches Amt. (1884). Statistik des deutschen Reichs. Band 2. Berlín: Puttkammer \& Mühlbrecht.

Kaiserliches Statistisches Amt. (1897). Statistik des deutschen Reichs. Band 109. Beríin: Puttkammer \& Mühlbrecht.

Kaiserliches Statistisches Amt. (1910). Statistik des deutschen Reichs. Band 240. Berlín: Puttkammer \& Mühlbrecht.

Kampmann, C. (2008). Europa und das Reich im Dreißigjährigen Krieg. Stuttgart: Kohlhammer.

Karadja, M. y Prawitz, E. (2019). Exit, voice, and political change: Evidence from Swedish mass migration to the United States. Journal of Political Economy, 127(4), 1864-925.

Kelly, M. (2019). The standard errors of persistence. CEPR discussion paper 13783, Londres.

Kersting, F. (2017). Coal and blood: Industrialization and the rise of nationalism in Prussia before 1914. CRC TRR 190 Rationality and Competition Discussion Paper 52, Múnich.

Kersting, F., Wohnsiedler, I. y Wolf, N. (2020). Weber revisited: The protestant ethic and the spirit of nationalism. Ann Arbor, MI: Interuniversity Consortium for Political and Social Research, [https://doi. org/10.3886/E119604V1].

Knabe, F. (2000). Sprachliche Minderheiten und nationale Schule in Preußen zwischen 1871 und 1933: Eine bildungspolitische Analyse. Münster: Waxmann.

Königlich Statistisches Bureau. (1875). Preussische Statistik Band 30. Verlag des Königlichen Statistischen Bureaus.

Lamberti, M. (1989). State, Society, and the Elementary School in Imperial Germany. Oxford: Oxford University Press.

Lehmann, H. y Roth, G. (1995). Weber's Protestant ethic: origins, evidence, contexts. Cambridge: Cambridge University Press.

Lehmann H., S. y Wahl, F. (2017). Savings banks and the industrial revolution in Prussia supporting regional development with public financial institutions. CEPR discussion paper 12500, Londres.

Lusardi, A. y Mitchell, O. S. (2011). Financial literacy around the world: An overview. NBER working paper Series 17107, Cambridge, Mass.

MacKinnon, M. H. (1995). The longevity of the thesis. En H. Lehmann y G. Roth (eds.), Weber's Protestant Ethic: Origins, evidence, context (pp. 211-243). Cambridge: Cambridge University Press.

Margo, R. A. (2017). The integration of economic history into economics. NBER Working Paper Series No. 23538, Cambridge, MA.

Martin, R. (1912). Jabrbuch des Vermögens und Einkommens der Millionäre in Preußen. Berlín: Verlag W. Herlet. 
Molik, W. (1998). Inteligencja polska w dziewietnastowiecznym Poznaniu. Liczebnosc i strukture zawodowa. En J. Wiesiolowski (ed.), Inteligencja Poznanska. Historia I wspomnienia (pp. 9-33). Poznan: Kronika Miasta Poznania.

Mommsen, W. J. (2004). Max Weber und die deutsche Politik 1890-1920. Tubinga: Mohr Siebeck.

Nolan, P. y Lenski, G. (2014). Human societies: An introduction to macrosociology. Oxford: Oxford University Press.

Offenbacher, M. (1901). Konfession und soziale Schichtung. Eine Studie über die wirtschaftliche Lage der Katholiken und Protestanten in Baden. Tubinga: J.C.B. Mohr (Paul Siebeck).

Politische Abteilung des königlichen Polizeipräsidiums in Posen. (1909). Rechenschaftsberichte für das Jahr 1907 (Sonderausgabe des Gesamtüberblicks über die polnische Tagesliteratur). Posen: Merzbach'sche Buchdruckerei.

Rubin, J. (2014). Printing and Protestants: An empirical test of the role of printing in the Reformation. Review of Economics and Statistics, 96(2), 270-286.

Schilling, H. (1994). Höfe und Allianzen. Deutschland 1648-1763. Berlín: Siedler.

Schindling, A. y Ziegler, W. (1989). Die Territorien des Reichs im Zeitalter der Reformation und Konfessionalisierung: Land und Konfession 15001650: Band 1 Der Südosten. Münster: Aschendorff.

Schindling, A. y Ziegler, W. (1992). Die Territorien des Reichs im Zeitalter der Reformation und Konfessionalisierung: Land und Konfession 15001650: Band 4 Mittleres Deutschland. Münster: Aschendorff.

Schindling, A. y Ziegler, W. (1993a). Die Territorien des Reichs im Zeitalter der Reformation und Konfessionalisierung: Land und Konfession 1500-1650: Band 2 Der Nordosten. Münster: Aschendorff.

Schindling, A. y Ziegler, W. (1993b). Die Territorien des Reichs im Zeitalter der Reformation und Konfessionalisierung: Land und Konfession 1500-1650: Band 5 Der Südwesten. Münster: Aschendorff.

Schindling, A. y Ziegler, W. (1995). Die Territorien des Reichs im Zeitalter der Reformation und Konfessionalisierung: Land und Konfession 15001650: Band 3 Der Nordwesten. Münster: Aschendorff.

Schindling, A. y Ziegler, W. (1996). Die Territorien des Reichs im Zeitalter der Reformation und Konfessionalisierung: Land und Konfession 15001650: Band 6 Nachträge. Münster: Aschendorff.

Schönpflug, D. (2013). Die Heiraten der Hohenzollern. Verwandtschaft, Politik und Ritual in Europa 1640-1918. Göttingen: Vandenhoeck und Ruprecht.

Schutte, C. (2008). Die Königliche Akademie in Posen (1903-1919). Marburgo: Herder Institut.

Scott, A. (2009). Book Review: Jack Barbalet, Weber, Passion and Profits. Canadian Journal of Sociology, 34(3), 903-905.

Spenkuch, J. L. (2017). Religion and work: Micro evidence from contemporary Germany. Journal of Economic Behavior E Organization, 135(3), 193-214. 
Spenkuch, J. L. y Tillmann, P. (2018). Elite influence? Religion and the electoral success of the Nazis. American Journal of Political Science, 62(1), 19-36.

Suesse, M. y Wolf, N. Rural transformation, inequality, and the origins of microfinance. Journal of Development Economics, 143(2020), 102-429.

Tabellini, G. (2008). The scope of cooperation: Values and incentives. Quarterly Journal of Economics,123(3), 905-950.

Trende, A. (1957). Geschichte der deutschen Sparkassen bis zum Anfang des 20. Jahrhunderts. Stuttgart: Deutscher Sparkassen-Verlag.

Troeltsch, E. (1922). Der Historismus und seine Probleme. Tubinga: Mohr.

Trzeciakowski, L. (1970). Kulturkampf w zaborze pruskim. Poznan: Wydawn.

Verband der Ärzte Deutschlands. (1908). Verzeichnis der Ärzte im Deutschen Reiche und deutscher Ärzte im Auslande. Leipzig: Verband der Ärzte Deutschlands.

Von Knebel D., H. (1907). Das Sparkassenwesen in Preußen. Berlín: Mittler.

Weber, M. (1895). Der Nationalstaat und die Volkswirtschaftspolitik. Akademische Antrittsrede. En W. Mommsen (ed.), Max Weber Gesamtausgabe. Band 4. Landarbeiterfrage, Nationalstaat und Volkswirtschaftspolitik. Schriften und Reden 1892-1899 (pp. 543-74). Tubinga: J.C.B. Mohr (Paul Siebeck).

Weber, M. (1904). Die protestantische Ethik und der Geist des Kapitalismus. Archiv für Sozialwissenschaften und Sozialpolitik, 20(1), 1-54.

Weber, M. (1905). Die protestantische Ethik und der Geist des Kapitalismus. Archiv für Sozialwissenschaften und Sozialpolitik , 21(1), 1-110.

Weber, M. (1930). The Protestant ethic and the spirit of capitalism. T. Parsons, (trad.), Londres: George Allen \& Unwin.

Wehler, H.-U. (2006). Deutsche Gesellschaftsgeschichte. Dritter Band 1849-1914. Múnich: C.H. Beck.

Wolf, N. (2009). Was Germany Ever United? Evidence from Intra- and International Trade, 1885-1933. Journal of Economic History, 69(3), 846-881.

Zeumer, K. (ed.). (1913). Quellensammlung zur Geschichte der Deutschen Reichsverfassung in Mittelalter und Neuzeit. 2, Von Maximilian I. bis 1806. Tubinga: J.C.B. Mohr (Paul Siebeck).

Zimmerman, A. (2006). Decolonizing Weber. Postcolonial Studies, 9(1), 53-79. 